\title{
Rebound Discharge in Deep Cerebellar Nuclear Neurons In Vitro
}

\author{
Reza Tadayonnejad • Dustin Anderson • \\ Michael L. Molineux • W. Hamish Mehaffey • \\ Kusala Jayasuriya $\cdot$ Ray W. Turner
}

Published online: 16 April 2010

(C) The Author(s) 2010. This article is published with open access at Springerlink.com

\begin{abstract}
Neurons of the deep cerebellar nuclei (DCN) play a critical role in defining the output of cerebellum in the course of encoding Purkinje cell inhibitory inputs. The earliest work performed with in vitro preparations established that DCN cells have the capacity to translate membrane hyperpolarizations into a rebound increase in firing frequency. The primary means of distinguishing between DCN neurons has been according to cell size and transmitter phenotype, but in some cases, differences in the firing properties of DCN cells maintained in vitro have been reported. In particular, it was shown that large diameter cells in the rat DCN exhibit two phenotypes of rebound discharge in vitro that may eventually help define their functional roles in cerebellar output. A transient burst and weak burst phenotype can be distinguished based on the frequency and pattern of rebound discharge immediately following a hyperpolarizing stimulus. Work to date indicates that the difference in excitability arises from at least the degree of activation of T-type $\mathrm{Ca}^{2+}$ current during the immediate phase of rebound firing and $\mathrm{Ca}^{2+}$-dependent $\mathrm{K}^{+}$channels that underlie afterhyperpolarizations. Both phenotypes can be detected following stimulation of Purkinje cell inhibitory inputs under conditions that preserve resting membrane potential and natural ionic gradients. In this paper,
\end{abstract}

R. Tadayonnejad · D. Anderson · M. L. Molineux $\cdot$

W. H. Mehaffey $\cdot$ K. Jayasuriya $\cdot$ R. W. Turner

Department of Cell Biology \& Anatomy,

Hotchkiss Brain Institute, University of Calgary,

Calgary, Alberta, Canada T2N 4N1

R. W. Turner $(\bowtie)$

Hotchkiss Brain Institute, HRIC 1AA14, University of Calgary,

3330 Hospital Dr. N.W.,

Calgary, Alberta, Canada T2N 4N1

e-mail: rwturner@ucalgary.ca

URL: http://www.ucalgary.ca/ rwturner/ we review the evidence supporting the existence of different rebound phenotypes in DCN cells and the ion channel expression patterns that underlie their generation.

Keywords Purkinje cell · DCN · Afterhyperpolarization . Rebound bursts · T-type channel

\section{Introduction}

Neurons of the DCN face the task of encoding and communicating all information processed in the overlying cortex in the form of inhibitory input from Purkinje cells. Extensive work in in vitro preparations provide evidence that they may accomplish this in part through intrinsic membrane properties that generate a rebound burst of spikes following inhibitory stimuli. However, the identity of cells capable of eliciting rebound bursts or the relative magnitude of this output in relation to motor behaviors remains to be determined. Previous work described differences in the structure and ionic basis for evoked activity between small diameter (presumed GABAergic) neurons and the larger diameter neurons taken to represent excitatory output neurons [1-3]. Several studies have examined the ion channels that control DCN cell spike output $[1,2$, 4-6] and the ionic basis for rebound discharge using a wide range of in vitro preparations $[1,2,7-10]$. All studies that have used direct current-evoked membrane hyperpolarizations in vitro report the ability to generate rebound increases in firing frequency, albeit often from potentials that exceed the expected physiological range of membrane voltage deflections $[1,2,7,10-12]$. The ability to evoke rebound depolarizations or increases in spike firing following inhibitory synaptic stimulation in vitro has been reported in several studies $[2,9,10,13-16]$, although the 
ability to record synaptically evoked rebound bursts in vitro or in vivo was recently questioned [17]. A rebound-like or late increase in spike firing has also been seen with direct stimulation of the inferior olive or pontine nuclei in vivo [18-23]. A similar increase in firing following a period of inhibition in DCN cells has been described in relation to sensory input, arm or eye movements, and eyelid blink responses [22, 24-31]. However, the exact relationship between these changes in firing frequency in vivo and the intrinsic membrane properties that drive rebound bursts in vitro have not been fully determined. This is particularly the case when at least some of the late increase in firing of DCN cells in vivo can include coincident excitatory synaptic input $[22,25]$. The potential for differences in the ionic properties of DCN cells to shape these responses is also unknown.

Studies in vitro have focused primarily on the ability for large diameter DCN cells to generate rebound discharge, with most studies reporting no difference in the electroresponsiveness of large diameter cells. Cases can be found, however, where differences begin to become apparent. For instance, one study grouped DCN cells into "regular spiking" or "bursting" cells based on their response to depolarizing current injection and the nature of rebounds following current-evoked membrane hyperpolarizations [12]. The prevalence of these firing patterns was later reported as $\sim 44 \%$ of cells exhibiting burst discharge and the rest a tonic response [15]. The amplitude and kinetics of low voltage-activated (LVA) current recorded at the end of a hyperpolarizing step command in DCN cells was also reported to fall into two general groups [32]. Consistent with this, we recently gained evidence for two distinct phenotypes of rebound burst output in large diameter neurons [7] that can also be detected following inhibitory synaptic stimulation in vitro [16]. The potential then exists for these different phenotypes to correspond to cells that exhibit different rates and timing of discharge in the intact circuit. In this review, we summarize the evidence supporting the existence for different phenotypes of rebound burst discharge in large diameter rat DCN cells recorded in the in vitro slice preparation and our current state of knowledge of the underlying ionic basis for these distinctions.

\section{Methods}

All recordings were obtained using patch clamp techniques in parasagittal cerebellar slices prepared from P12-P18 Sprague-Dawley rats and maintained in vitro at $33-35^{\circ} \mathrm{C}$ according to the procedures detailed in [8]. Recordings were focused entirely on large diameter cells $(>15 \mu \mathrm{m})$ visually identified using differential interference contrast optics and infrared light transmission and in the interpositus nucleus unless otherwise noted. No attempt was made to distinguish between anterior and posterior divisions of the interpositus nucleus. External aCSF contained (in $\mathrm{mM}$ ): $125 \mathrm{NaCl}, 3.25 \mathrm{KCl}, 1.5 \mathrm{CaCl}_{2}, 1.5 \mathrm{MgCl}_{2}, 25 \mathrm{NaHCO}_{3}$, and $25 \mathrm{D}$-glucose, $\mathrm{pH}$ 7.4. The internal electrolyte for whole cell recordings was (in $\mathrm{mM}$ ): $130 \mathrm{~K}$-gluconate, 0.1 EGTA, 10 HEPES, $7 \mathrm{NaCl}, 0.3 \mathrm{MgCl}_{2}$, with 5 di-tris-creatine phosphate, 2 Tris-ATP, and 0.5 Na-GTP, pH7.3, with $\mathrm{KOH}$ $[7,8,16]$. Using these solutions, the reversal potentials of key ionic species according to the Nernst equation at $35^{\circ} \mathrm{C}$ were: $E_{\mathrm{Cl}}-75.7 \mathrm{mV}, E_{\mathrm{Na}}+55 \mathrm{mV}$, and $E_{\mathrm{K}}-97.2$. On-cell recordings were carried out by forming a high-resistance seal to the membrane with patch electrodes containing either a HEPES-buffered aCSF (in $\mathrm{mM}$ ): $150 \mathrm{NaCl}, 3.25$ $\mathrm{KCl}, 1.5 \mathrm{CaCl}_{2}, 1.5 \mathrm{MgCl}_{2}, 10$ HEPES, and 25 D-glucose, $\mathrm{pH} 7.4$, or the K-gluconate-based internal solution above. A calculated junction potential of $-10 \mathrm{mV}$ for the K-gluconate electrolyte was subtracted from potentials recorded in current clamp mode and to all values presented here. The amplitude of spike afterpotentials was calculated with respect to the voltage threshold of spike discharge, measured according to the maximal change in $\mathrm{d} V / \mathrm{d} t$ on the rising edge of the response as $-48 \pm 3.7 \mathrm{mV}$ (transient burst, $n=7$ ) and $-48 \pm 1.8 \mathrm{mV}$ (weak burst, $n=7$ ) [7]. Voltage clamp recordings of LVA inward current were obtained using an internal electrolyte consisting of $(\mathrm{mM})$ : $\mathrm{CsCl}$ (100), $\mathrm{KCl}$ (10), EGTA (10), $\mathrm{NaCl}(7), \mathrm{MgCl}_{2}(0.3)$, HEPES (10), with TTX (200 nM), and $\mathrm{CsCl}(1-2 \mathrm{mM})$ in the bath (no junction potential subtracted). Established protocols [33] were used to cotransfect tSA-201 cells with cDNA for $\alpha 1 \mathrm{E}$ (R-type $\mathrm{Ca}^{2+}$ ) and the associated $\beta 1 \mathrm{~b}$ and $\gamma 2-\delta$ subunits $(3 \mu \mathrm{g} / \mathrm{ml})$ and plated on glass coverslips for recordings at $32^{\circ} \mathrm{C}$. For the majority of recordings, all excitatory synaptic responses were blocked using $25 \mu \mathrm{M}$ DL-2-amino-5-phosphonopentanoic acid (DL-AP5) and $10 \mu \mathrm{M}$ 6,7-dinitroquinoxolinedione, and inhibitory responses using $50 \mu \mathrm{M}$ picrotoxin $[7,8,16]$. Stimulus electrodes used to evoke IPSPs were placed at a site dorsal and outside the nucleus boundary to avoid activating any local networks, unless otherwise specified.

Centroid clustering and squared Euclidean distance analysis was performed in SPSS and data fits in Matlab or PClamp software. Average values represent mean \pm SEM, and statistical significance was calculated using Student's $t$ tests and one-way ANOVA with Tukey post hoc comparisons $\left({ }^{*} p<0.05,{ }^{* *} p<0.01,{ }^{* * *} p<0.001\right)$.

\section{Results}

Spontaneous Activity

Large diameter neurons $(>15 \mu \mathrm{m})$ in the DCN characteristically show multiple radiating dendritic branches $[1,12$, 
34, 35] and a spike response associated with three afterpotentials: a fast afterhyperpolarization (fAHP), a depolarizing afterpotential (DAP), and a slow afterhyperpolarization (sAHP; Fig. 1a, b). Comparison of this activity to previous work indicates that the cells we restrict our recordings to correspond most closely to the type I category of Czubaryko et al. [1] and the large diameter $\operatorname{GAD}(-)$ cells of Uusisaari et al. [3] that also show a set of three afterpotentials. The intrinsic spontaneous activity inherent to DCN cells has been well characterized in in vivo and in vitro preparations. $\mathrm{DCN}$ cells are reported to tonically discharge at a rate of $\sim 35 \mathrm{~Hz}$ in the awake mouse, rat, and cat [36-38]. For DCN cells maintained in a variety of in vitro preparations, including tissue slices, organotypic preparations, or dissociated cells, the spontaneous firing rate is typically in the lower range of $10-37 \mathrm{~Hz}[1,3,5,12$, $17,39,40]$. The tonic firing rates of DCN cells reported in previous work can be compared to that which we encounter in large diameter cells in a rat slice preparation in Table 1. Spike discharge recorded using on-cell patch recordings with aCSF as the electrolyte to avoid disrupting cell contents reveal a baseline firing rate of $\sim 18 \mathrm{~Hz}$. This firing rate was also comparable to on-cell recordings when using the electrolyte for intracellular recordings and to that recorded following break-in to whole cell configuration in a subset of cells (Table $1 ; n=12$ ) [16]. Note that following break-in to whole cell mode and with no baseline current injection, the values for both tonic firing rate and of a rebound increase in frequency were similar to those of oncell recordings (Table 1) [1, 16].

Burst-like activity in the resting state has been observed in $40-50 \%$ of DCN cells in ketamine-anesthetized rats [26]. Bursting in the resting state has also been reported in awake, unanesthetized mice in the form of at least spike doublets, with the extent and duration of bursts increasing with age in a model of dystonia [38]. The relationship of this activity to transient or weak burst phenotypes recorded in vitro is not known at this time as we do not detect any difference in the rate or pattern of firing in the resting state of cells in the slice preparation. DCN cells have further been reported capable of exhibiting a slow oscillatory swing in membrane potential in vitro with a period of seconds, with high-frequency $\mathrm{Na}^{+}$spike discharge generated on the depolarizing phase of the oscillation $[1,2]$. In some cases, this was reported to be more prevalent during imposed membrane hyperpolarizations [2], and with some of the first patch recordings, slow oscillations were taken as a hallmark of "type I' cells [1]. Similar activity is now recognized to occur upon internal perfusion of BAPTA or high concentrations of EGTA [2] (M.L. Molineux, unpublished observations) or block of either N-type $\mathrm{Ca}^{2+}$ channels [41] or SK $\mathrm{K}^{+}$channels [2, 42]. Together, these results reveal a coupling between $\mathrm{N}$-type $\mathrm{Ca}^{2+}$ influx and
SK $\mathrm{K}^{+}$channels to generate a large portion of the AHP. By comparison, when using EGTA at a concentration of $0.1 \mathrm{mM}$ in the electrolyte, we rarely observe slow oscillatory activity. We thus interpret slow oscillations to reflect an abnormal state of firing subsequent to the loss of $\mathrm{Ca}^{2+}$-dependent activation of $\mathrm{K}^{+}$currents that otherwise establish a stable interspike interval $[2,41,43]$ and reject cells that exhibit slow oscillatory shifts in membrane potential.

Normal activity in DCN cells in vitro is then typically taken as a stable rate of tonic firing. To facilitate comparisons between cells in vitro, we also routinely apply low levels of steady current injection $(<50 \mathrm{pA})$ to position the membrane potential at a nominal value of $-60 \mathrm{mV}$ at the trough of the AHP, establishing a baseline firing rate of $13.6 \pm 6.1 \mathrm{~Hz}(n=$ 30 , transient and weak burst cells combined and junction potential subtracted; see "Methods").

\section{Rebound Firing}

Most studies in vitro have focused on the properties and ionic mechanisms underlying the rebound response immediately following a hyperpolarizing stimulus $[1,2,4,5,7-$ 10]. The occurrence of a transient burst of spike discharge in $\sim 44 \%$ of cells in response to depolarizing current injection had been reported in the slice preparation [12, 15] and in a lower percentage of cells in an organotypic preparation [44]. When applying hyperpolarizing current steps, we found that rebound responses at the end of the pulse fell into two phenotypes referred to as a transient burst or weak burst response (Fig. 1c, d) [7, 8]. A similar distinction in weak vs strong rebound firing frequency was recently noted for large diameter cells in the mouse DCN [45]. These authors found that cells could also be distinguished on the basis of a non-adapting spike response to depolarizing current injection in weak burst cells and an adapting short-duration burst in strong burst cells [45]. The extent to which these differences in spike firing adaption applies to weak and transient burst cell phenotypes in the rat DCN has not yet been examined.

Burst Definition In our initial studies, we used qualitative aspects of rebound bursts to classify cells as exhibiting a transient or weak burst phenotype [7,8]. To obtain consistent results on rebound discharge between laboratories, it will be important to move from these subjective analyses to a statistical definition that can be readily compared. We recently used a statistical analysis to define both the occurrence and duration of bursts [16], a procedure that proved to be entirely consistent with our initial qualitative assessments. We define a burst as the duration of spike firing in which the instantaneous frequency following a membrane hyperpolarization increases by at 
Fig. 1. Deep cerebellar cells exhibit two phenotypes of rebound discharge. a $\mathrm{A}$ biocytin-filled large diameter cell. b Expanded view of the fAHP, DAP, and sAHP recorded in large diameter neurons and an example of tonic firing near resting potential. c, d Representative recordings of rebound responses to a set of hyperpolarizing current steps in vitro. The immediate rebound responses are enlarged as insets and the initial rebound response is indicated in color. e Representative instantaneous frequency plots of rebound firing in transient and weak burst cells. Time 0 represents the end of a 500-ms hyperpolarizing step to $-80 \mathrm{mV}$. Note the difference in scales for frequency between transient and weak burst cells. f Average values of the rate of tonic and rebound firing for transient $(n=$ $47)$ and weak burst $(n=62)$ cells following a hyperpolarizing step to $-90 \mathrm{mV}(1 \mathrm{~s}, p<0.05)$. g Plot of the maximum rebound burst frequencies of cells in response to a membrane hyperpolarization to $-80 \mathrm{mV}$ across all $\mathrm{DCN}$ nuclei ( $500 \mathrm{~ms}, n=175$, bin width $25 \mathrm{~Hz}$ ). A bimodal distribution of frequencies appears, as supported by cluster analysis (squared Euclidian distance of 2). $\mathbf{h}$ Input resistance for all cells shown in $\mathbf{g}$ (bin width $50 \mathrm{M} \Omega$ ). $\mathbf{i}$ Plot of the maximum rebound frequency recorded for cells in $\mathbf{g}$ and $\mathbf{h}$ in relation to input resistance. Dashed lines in $\mathbf{g}$ and $\mathbf{i}$ depict the approximate boundary between the two defined clusters of data points that range from 10 to 113 and 132 to $249 \mathrm{~Hz}$. The data in a and $\mathbf{f}$ were modified from [7, 8]. The absolute membrane potentials at the trough of the AHP and during current-evoked hyperpolarizations are shown in $\mathbf{b}-\mathbf{d}$ a
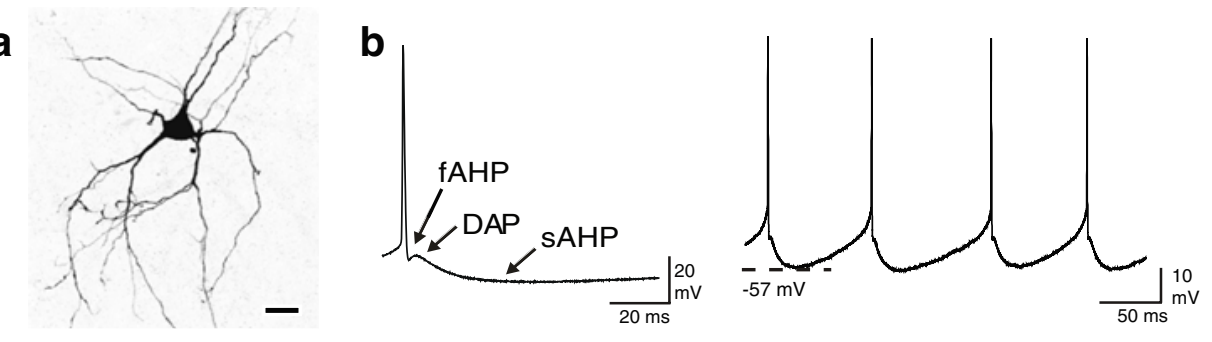

C

Transient Burst cell

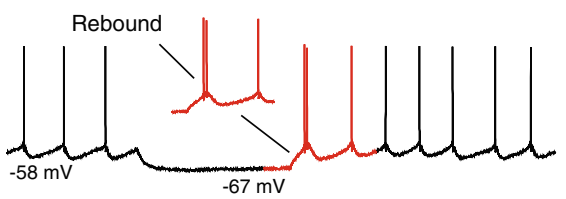

d
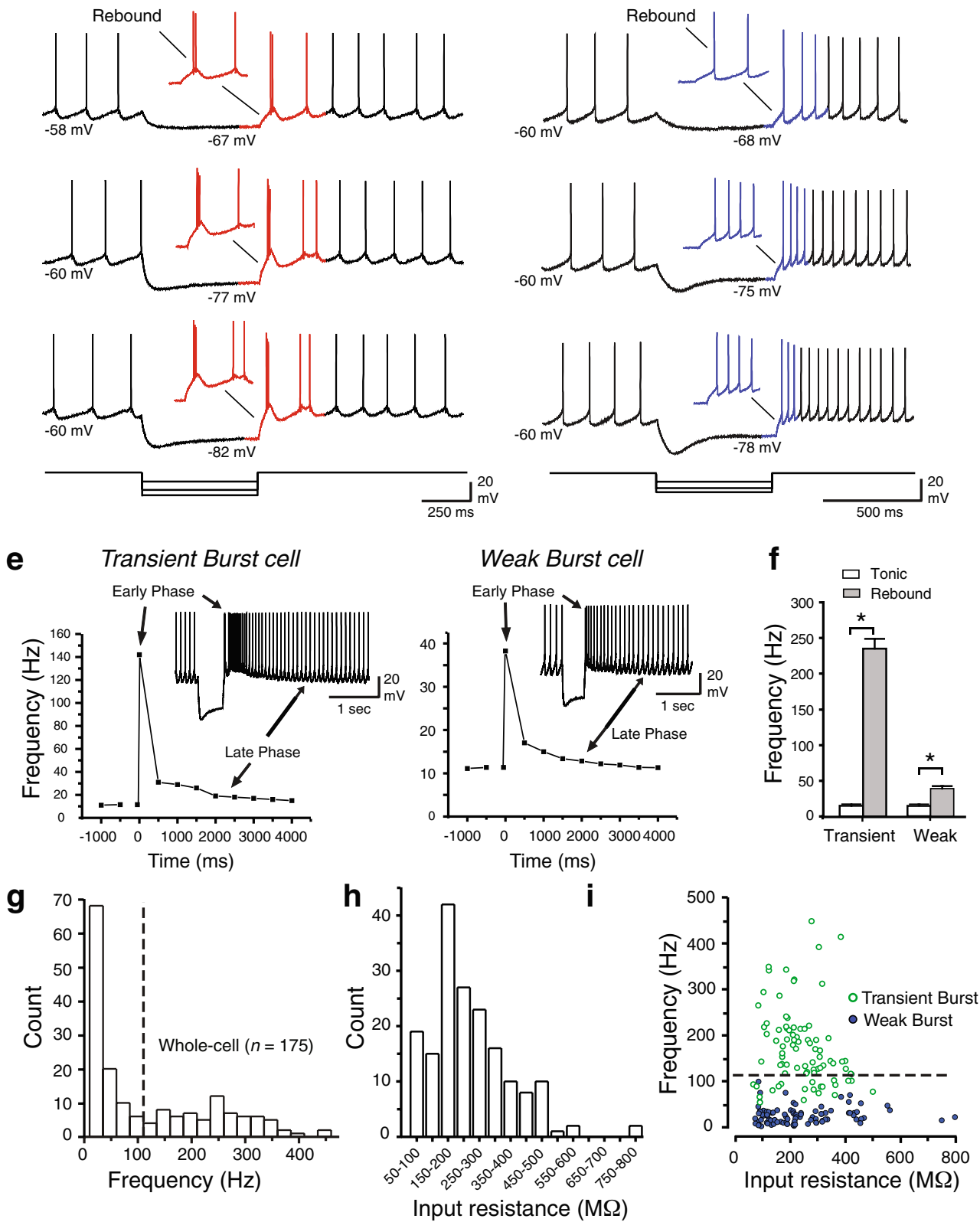

least 2 standard deviations beyond the mean tonic firing rate calculated over a 1-s time frame preceding the hyperpolarizing stimulus [16]. We note that the rebound response includes both an initial early phase of highfrequency firing as well as a prolonged late phase of increased firing frequency that can last up to several seconds (Fig. 1e). We define any increase in instantaneous frequency following a hyperpolarizing stimulus that exceeds our statistical criterion as representing part of the rebound burst response (early and late phase). 
Table 1 Spike properties in whole cell and on-cell recordings of DCN neurons

\begin{tabular}{llcccc}
\hline & \multicolumn{2}{l}{ Transient burst } & & \multicolumn{2}{l}{ Weak burst } \\
\cline { 2 - 3 } \cline { 5 - 6 } & Tonic freq. (Hz) & Rebound freq. (Hz) & & Tonic freq. (Hz) & Rebound freq. (Hz) \\
\hline On-cell (aCSF) & $17.8 \pm 3.02(16)$ & $73.8 \pm 9.58$ & & $18.6 \pm 1.8(12)$ & $13.57 \pm 1.95$ \\
On-cell (K-Gluc.) & $18.4 \pm 3.13(5)$ & $69.7 \pm 8.83$ & & $19.2 \pm 4.0(7)$ & $12.3 \pm 1.23$ \\
Whole cell (K-Gluc.) & $17.6 \pm 2.16(5)$ & $58.6 \pm 7.83$ & & $17.8 \pm 3.24(7)$ & $11.7 \pm 1.17$ \\
\hline
\end{tabular}

Shown are mean values of tonic spike output under resting conditions and during rebound bursts following a 100-Hz, ten-stimulus train of Purkinje cell inputs (60-70\% of maximal intensity). Rebound burst frequencies reflect the maximum frequency attained above the baseline tonic firing rate determined over a 1-s period preceding the stimulus train according to a statistical measure (see "Methods"). No significant differences were detected between on-cell or whole cell recordings. Whole cell recordings were made without applied current. Sample sizes are shown in parentheses. Table is modified from [16]

aCSF artificial cerebrospinal fluid, $K$-Gluc. potassium gluconate

All of our work on the ionic basis of rebound bursts has been centered on the early phase of rebound in which the maximal frequency of rebound is typically found within the first five spikes following a hyperpolarizing stimulus. The later phase of rebound depolarization was examined in some of the first in vitro recordings of DCN cells [9] and reported by several others $[1-3,10,12]$. Sodium spike discharge was shown to support a significant portion of the $\mathrm{Ca}^{2+}$ influx that can be recorded in soma and dendrites of DCN cells during rebound depolarization, revealing the action of high voltage-activated (HVA) $\mathrm{Ca}^{2+}$ channels $[10,13,44]$. A role for $\mathrm{HVA} \mathrm{Ca}^{2+}$ current was further suggested by an increase in the intensity of rebound bursts evoked by current injection or with inhibitory synaptic activation at depolarized levels of resting potential [2, 13], a process that should inactivate LVA $\mathrm{Ca}^{2+}$ currents. Early reports also identified a set of inward currents that contribute to a plateau depolarization triggered by depolarizing current pulses in vitro (i.e., persistent $\mathrm{Na}^{+}, \mathrm{HVA} \mathrm{Ca}{ }^{2+}$ ) $[1,4,6,9$, $13,44]$. Most recently, a role for all subtypes of $\mathrm{HVA} \mathrm{Ca}^{2+}$ channels ( $\mathrm{L}, \mathrm{N}, \mathrm{P} / \mathrm{Q}$ and $\mathrm{R}$ ) was found in relation to spike output during the later phase of rebound firing [10]. We do not currently know if the properties of the late phase of rebound firing differ between transient and weak burst cells. All of the work discussed below on transient and weak burst cell types thus pertains exclusively to the early phase of rebound, unless otherwise noted.

Transient vs Weak Rebound Burst Discharge We find that a "transient burst" cell has the capacity to discharge an initial transient rebound burst of two to five spikes at frequencies typically $>100 \mathrm{~Hz}$ and up to $450 \mathrm{~Hz}$ above the initial baseline firing rate (Fig. 1c-f). By comparison, "weak burst" cells do not show a transient burst response, but instead attain rebound firing rates typically $<100 \mathrm{~Hz}$ beyond the tonic baseline firing rate for all levels of preceding hyperpolarization (Fig. 1d-f). Figure 1g illus- trates a bar plot comparing the maximum rebound burst frequencies identified for cells following a common membrane hyperpolarization to $-80 \mathrm{mV}(500 \mathrm{~ms})$. In order to use the maximum number of points, we plotted cells recorded across all DCN nuclei $(n=175)$. In support of these distinctions, we found a bimodal distribution of burst frequencies with peaks at $\sim 15$ and $\sim 250 \mathrm{~Hz}$ beyond baseline firing rate. The validity of this interpretation was supported by a hierarchical cluster analysis that reported two distinct groups (a squared Euclidian distance of 2) within the frequency ranges of $10-113$ and $132-459 \mathrm{~Hz}$. Nevertheless, there is a region of current-evoked spike output near $\sim 120 \mathrm{~Hz}$ where a small number of cells in these populations $(\sim 17 \%)$ overlap (Fig. 1g, i). At this time, we still rely on qualitative criteria to classify the relatively small proportion of cells in this intermediate frequency range according to the presence or absence of a transient burst component.

As characteristically reported for DCN cells $[1,2,10$, $13,16,46]$, we find that the ability to evoke a rebound response depends on the level of preceding hyperpolarization for cells of either burst phenotype. The magnitude of rebounds thus progresses from little frequency increase for very low levels of hyperpolarization to more intense bursts as the hyperpolarization is increased (Fig. 1c, d). Depending on the duration and amplitude of the hyperpolarizing step, we find that rebound increases in frequency can be evoked for even relatively small hyperpolarizing steps that stay below the calculated $E_{\mathrm{Cl}}$ of $-75 \mathrm{mV}$ (i.e., top traces in Fig. 1c, d). In many cases, the transient burst component may not be evident for lower levels of current injection, but once evoked, it is distinguished by a subsequent hyperpolarization lasting $20-120 \mathrm{~ms}$ before returning to a more elevated rate of firing (Fig. 1c, e). As described in Molineux et al. [8], the cells we currently group together as weak burst cells can show a range of activity and frequency increases. It is thus possible that with future work, further distinctions between DCN cells in terms of 
spike output will become apparent, as suggested already in terms of transmitter co-expression and differential projection patterns of DCN cells [47-49]. For instance, in rare cases $(3 / 84)$, we encounter weak burst cells that show an initial single rebound spike followed by a longer AHP and then progressive shortening of the interspike interval before moving to a rebound increase in firing of $74.6 \pm 11.8 \mathrm{~Hz}$ above the initial tonic firing rate $(n=3, p<0.001$; not shown). However, under our recording conditions, a preceding hyperpolarization sufficient to change the firing rate leads to an increase in frequency in almost all cases shortly following the stimulus in both transient and weak burst cells (i.e., within five spikes).

One possible explanation for the different frequencies of output for these two burst phenotypes would be a difference in cell structure (i.e., size of the dendritic arbor) that could affect input resistance or burst output $[50,51]$. Despite repeated analyses, no clear evidence has been obtained to suggest that rebound burst properties of large diameter DCN cells relate to any structural differences (i.e., number of dendritic branches or branching pattern) $[1,3,8,12,35]$. The values of input resistance of large diameter transient and weak burst cells varies over a wide range (50-800 $\mathrm{M} \Omega$ ) and as a population distribute as a unimodal peak centered at $\sim 150-200 \mathrm{M} \Omega$ (Fig. 1h, i; $n=175$ ). Uusisaari et al. [3] used a measure of capacitance to correlate firing properties to cell surface area in a careful attempt to establish an electrophysiological signature that could be used to discriminate between $\operatorname{GAD}(-)$ and $\mathrm{GAD}(+)$ cells in mouse DCN. Although differences were found between small and large diameter cells, it is not apparent upon inspection of those measurements of any clear distinction among large diameter cells that would help differentiate between rebound phenotypes.
Transient and Weak Burst Phenotypes are Associated with Select T-Type $\mathrm{Ca}^{2+}$ Channel Isoforms

From the earliest studies of rebound discharge in DCN cells, it was suspected that the rebound burst derived at least in part from the activation of LVA (T-type) $\mathrm{Ca}^{2+}$ channels $[1,2,9,13,44,52]$. These channels have the property of being almost inactivated near resting potential, allowing membrane hyperpolarizations to regulate their availability according to the degree of recovery from inactivation. T-type $\mathrm{Ca}^{2+}$ channels belong to the Cav3 channel family that is comprised of three isoforms $\left(\alpha_{1 \mathrm{G}}\right)$ $\mathrm{Ca}_{\mathrm{v}} 3.1, \alpha_{1 \mathrm{H}} / \mathrm{Ca}_{\mathrm{v}} 3.2$, and $\left.\alpha_{1 \mathrm{I}} / \mathrm{Ca}_{\mathrm{v}} 3.3\right)$ that display distinct kinetic properties in heterologous expression systems [5355]. We recently examined the distribution of Cav3 channel isoforms in the DCN and other cerebellar neurons using polyclonal antibodies [7, 56]. This work demonstrated a widespread but cell-specific expression of Cav3 channel isoforms in cerebellar neurons, including DCN nuclei in which cells proved to be either negative or positive for Cav3 immunolabels (Fig. 2). To examine the degree of correlation between Cav3 channel expression and rebound burst phenotype, we first identified burst properties through recordings in vitro, filled the cells with neurobiotin, and then reacted tissue for Cav3 antibodies [7]. We found that transient burst cells were consistently positive for Cav3.1, but not Cav3.3 immunolabel (Fig. 2a). Conversely, weak burst cells were positive for Cav3.3, but not Cav3.1 immunolabel (Fig. 2b). No specific result was obtained with respect to the expression of Cav3.2. Thus, at this time, there is an established correlation between burst phenotype and Cav3.1 or Cav3.3 channel isoforms, while the potential role for Cav3.2 channels remains undetermined.

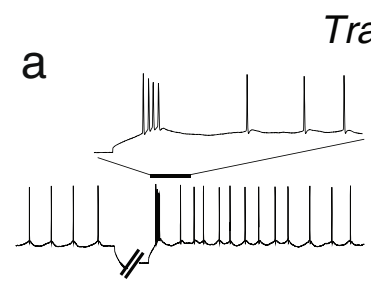

Transient Burst
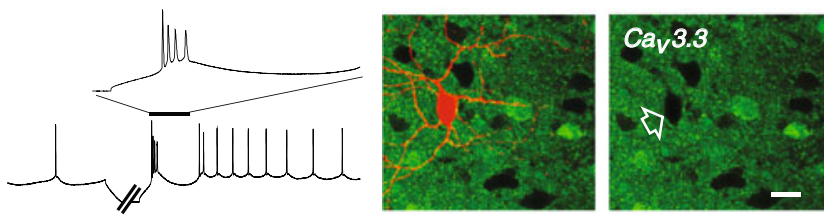

Fig. 2. Transient and weak Burst neurons are associated with select $\mathrm{Ca}_{\mathrm{v}} 3$ T-type $\mathrm{Ca}^{2+}$ channel isoforms. a, b Shown are recordings from transient burst (a) and weak burst neurons (b) in vitro and filled with biocytin for identification with streptavidin-Cy3. Filled neurons represented two dimensional extended projections of up to 60 images in a confocal stack and immunolabels a single image at $0.5 \mu \mathrm{m}$

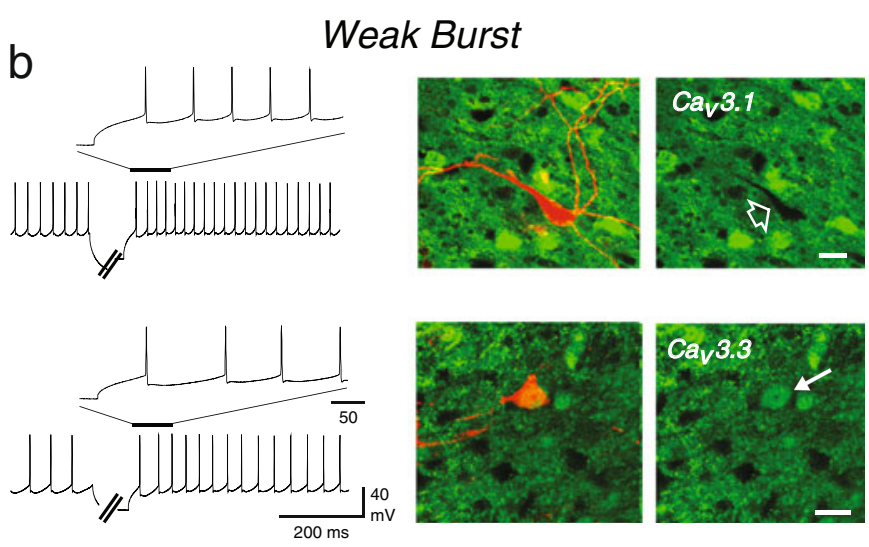

separation. a Transient burst cells are associated with a positive immunolabel for Cav3.1 (solid arrow), but not Cav3.3 (open arrow). b Weak burst cells are negative for Cav3.1 immunolabel (open arrow), but positive for Cav3.3 (solid arrow). Scale bars, $20 \mu \mathrm{m}$. Modified from [7] 
We further considered how burst patterns and Cav3 expression compare to putative excitatory or inhibitory large diameter neurons. For this, we used double-label immunocytochemistry to distinguish GAD-67-positive cells (GABAergic neurons) in relation to Cav3.1 or Cav3.3 expression as an indirect marker for burst properties [7]. We found that cells positive for $\mathrm{Ca}_{\mathrm{v}} 3.1$ immunolabel could be either $\mathrm{GAD}(+)$ or $\operatorname{GAD}(-)$, while cells that were $\mathrm{Ca}_{\mathrm{v}} 3.3-$ positive (weak burst) were all $\mathrm{GAD}(-)$ [7]. These studies then indicate that the transient burst $/ \mathrm{Ca}_{\mathrm{v}} 3.1$ phenotype can correspond to either non-GABAergic (excitatory) or GABAergic neurons, while a weak burst phenotype/ Cav3.3 expression appears to be restricted to excitatory neurons.

Transient and Weak Burst Phenotypes Differentially Activate T-Type $\mathrm{Ca}^{2+}$ Current

The Cav3.1 channel isoform had recently been associated with rebound burst discharge in that burst output is absent in thalamic relay cells [57] and hypothalamic paraventricular neurons [58] in Cav3.1 knockout mice. We also found that the strong rebound bursts and T-type current in lateral habenular neurons correlated with some of the most intense immunofluorescent labeling for Cav3.1 protein in the brain $[56,59,60]$. Our own survey of cells in cerebellum supports this distinction in that all cells that express Cav3.1 channels (Purkinje, Golgi, and transient burst DCN cells) are capable of exhibiting rebound bursts, while stellate cells that do not express Cav3.1 show no rebound frequency increase [7]. Yet, assigning this function to one particular isoform is difficult for most of these cells given the co-expression of Cav3.2 and Cav3.3 channels [7]. By contrast, the distinction in labeling for specific Cav3 isoforms in DCN cells provided one of the first demonstrations that Cav3 channel isoforms can be associated with different spike output patterns.

It should be noted that we found that the early phase of rebound bursts in DCN cells under our conditions were little affected by external perfusion of $\mathrm{Cs}^{+}$to block $\mathrm{I}_{\mathrm{H}}$, another channel known to contribute to rebound depolarizations in some cells [7]. Instead, physiological data support a key role for at least Cav3 channels in this process. Others had shown that DCN neurons can generate low threshold rebound $\mathrm{Ca}^{2+}$ spikes $[1,2,9]$ and rebound $\mathrm{Ca}^{2+}$ influx to step commands under voltage clamp [10, 15, 44, 61, 62]. Previous authors have also reported a dichotomy in the amount and rate of inactivation of LVA current recorded in DCN cells following a current-evoked hyperpolarization [32]. Our work suggested the same in finding that both transient and weak burst neurons can generate low threshold $\mathrm{Ca}^{2+}$ spikes, but with different probabilities [7]. All cells that were first shown to exhibit a transient burst phenotype consistently generated a rebound and low threshold broad spike in the presence of TTX and $\mathrm{Cs}^{+}$(Fig. 3a). The same result could be obtained with weak burst cells, but in approximately half the cases, uncovering a low threshold $\mathrm{Ca}^{2+}$ spike required the additional perfusion of general $\mathrm{K}^{+}$channel blockers [8]. Once revealed, the threshold for the LVA $\mathrm{Ca}^{2+}$ spike was similar in both cell types and consistent with T-type channels in exhibiting a voltage threshold of approx. $-60 \mathrm{mV}$. Final perfusion of $1 \mathrm{mM} \mathrm{Ni}^{2+}$ to block $\mathrm{Ca}^{2+}$ channels rapidly blocked the LVA spike in both cell types (Fig. 3a). Further support for a role for LVA $\mathrm{Ca}^{2+}$ current in generating the rebound response was provided by Alvina et al. [52] who showed that mibefradil and a more specific blocker of Ttype channels block rebound bursts evoked by current injection.

The current clamp recordings illustrated in Fig. 3a used a high concentration of $\mathrm{Ni}^{2+}(1 \mathrm{mM})$ which is not specific for Cav3 channels. The $\mathrm{Ca}^{2+}$-dependent spike immediately following a membrane hyperpolarization could then depend on the additional activation of $\mathrm{HVA} \mathrm{Ca}^{2+}$ currents during the rising phase of the LVA spike depolarization [10, 13, $44,62]$. To more carefully examine the contribution of Cav3 channels in transient and weak burst cells, we conducted voltage-clamp experiments to isolate the LVA $\mathrm{Ca}^{2+}$ current evoked near burst threshold $(-50 \mathrm{mV})$ [8]. These studies illustrated that a step from -90 to $-50 \mathrm{mV}$ evoked a fast-activating and fast-inactivating inward current (Fig. 3b) [62]. However, the current differed between transient and weak burst cells in exhibiting faster rates of activation and inactivation and on average approximately seven times greater magnitude in transient compared to weak burst cells. Sequential perfusion of $\mathrm{Cs}^{+}$to block $\mathrm{I}_{\mathrm{H}}$ (1-2 mM) and $\mathrm{Cd}^{2+}(50 \mu \mathrm{M})$ to block HVA Ca ${ }^{2+}$ channels had no effect. However, all inward current was blocked by $300 \mu \mathrm{M} \mathrm{Ni}^{2+}$, a concentration corresponding to that required to substantially block all Cav3 channel isoforms [63]. The combination of low threshold for activation, fast activation and inactivation, and sensitivity to low $\mathrm{Ni}^{2+}$ is consistent with identifying Cav3 channels as a major contributor to the LVA current recorded near threshold for a rebound response under normal conditions. Interestingly, the kinetic differences in rates of activation and inactivation in transient vs weak burst cells are also at least consistent with the properties of Cav3.1 vs Cav3.3 channels when expressed in isolation in heterologous expression systems [64]. A sequential comparison of rebound spike properties under current clamp conditions followed by measurement of LVA $\mathrm{Ca}^{2+}$ current at $-50 \mathrm{mV}$ under voltage clamp were revealing. These comparisons showed a very high correlation $(r=0.95)$ between the frequency and number of spikes during the early phase of rebound to the absolute amplitude of LVA current evoked at $-50 \mathrm{mV}$ for individual cells 


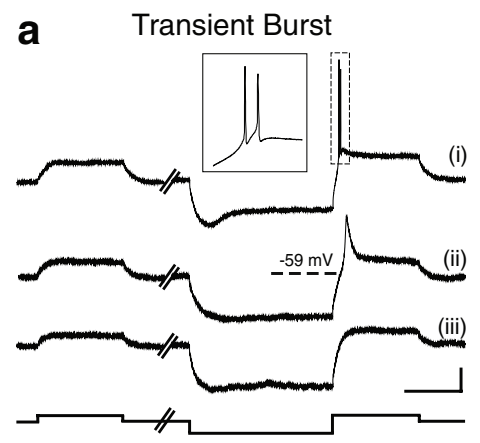

b
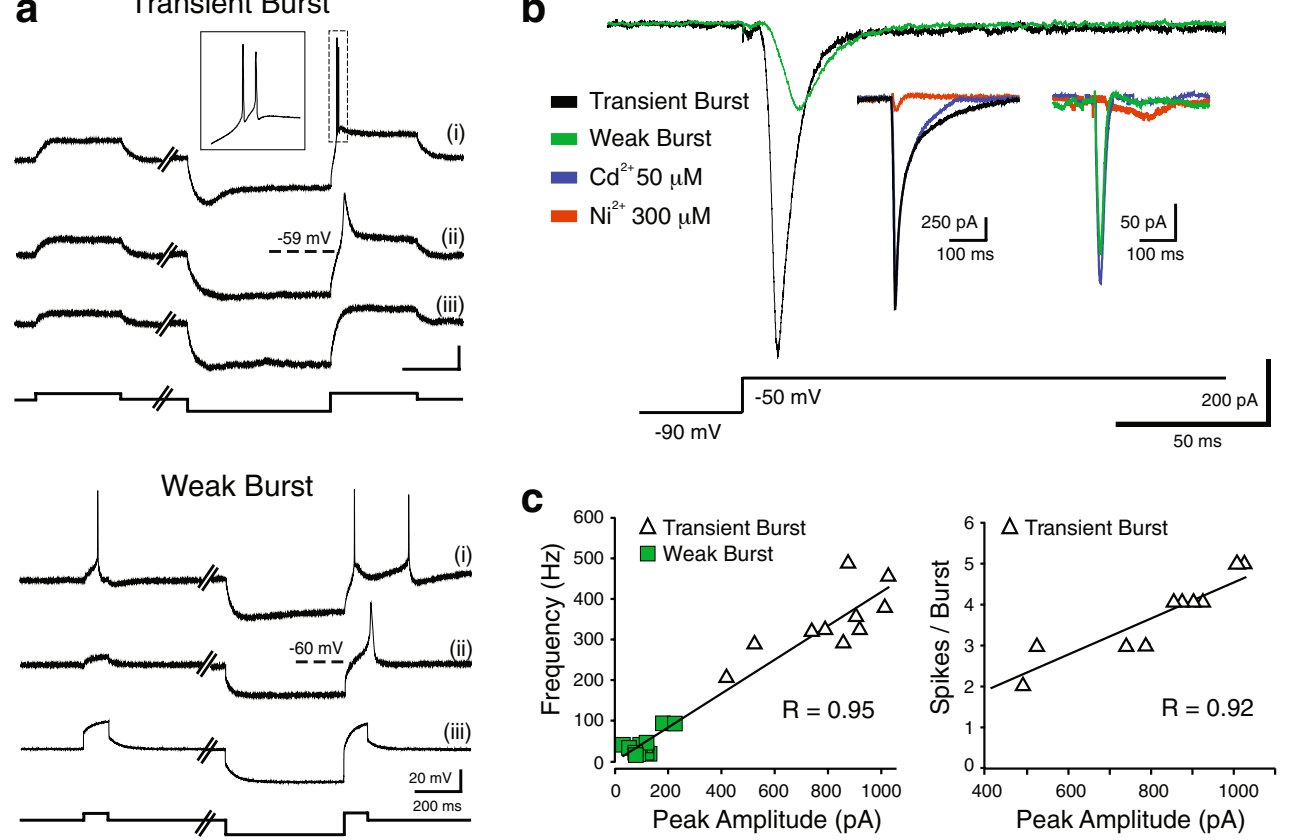

Fig. 3. Transient and weak burst phenotypes express LVA $\mathrm{Ca}^{2+}$ current and low threshold $\mathrm{Ca}^{2+}$ spikes during rebound discharge. a Deep cerebellar neurons exhibit LVA $\mathrm{Ca}^{2+}$ spikes. Shown are recordings in normal ACSF with $\mathrm{Na}^{+}$spike discharge intact $(i)$, after addition of TTX $(200 \mathrm{nM})$ and $\mathrm{Cs}+(2 \mathrm{mM})(\mathrm{ii})$, or TTX, Cs+, and $\mathrm{Ni}^{2+}(1 \mathrm{mM})$ to block $\mathrm{Ca}^{2+}$-dependent responses (iii). Dashed lines denote the voltage threshold for the LVA $\mathrm{Ca}^{2+}$ spike (ii) that is fully blocked by $\mathrm{Ni}^{2+}$ (iii). b Representative examples of LVA Ca ${ }^{2+}$ current recorded under whole cell voltage clamp from a transient and weak

(Fig. 3c) [8]. Thus, high frequencies of spike discharge during rebounds in transient burst cells were directly associated with LVA $\mathrm{Ca}^{2+}$ current in the range of $400 \mathrm{pA}-1 \mathrm{nA}$, while the lower spike frequencies in weak burst cells were associated with $<250 \mathrm{pA}$ current (Fig. 3c).

It is important to distinguish that these results do not specifically identify whether the amplitude of LVA current reflects a difference in $\mathrm{Ca}^{2+}$ channel voltage-dependence or channel density or if the apparent differences in kinetics for activation of the LVA current under voltage clamp in transient vs weak burst cells can be attributed specifically to Cav3.1 vs Cav3.3 channels, respectively. It also does not address the role of $\mathrm{HVA} \mathrm{Ca}^{2+}$ currents that are triggered by the LVA $\mathrm{Ca}^{2+}$ spike or $\mathrm{Na}^{+}$spikes under current clamp conditions nor the $\mathrm{Na}^{+} / \mathrm{Ca}^{2+}$-dependent plateau depolarization that could be expected to contribute to rebound depolarizations $[1,2,9,10,13,44]$. Although R-type $\mathrm{Ca}^{2}$ ${ }^{+}$channels have a similar sensitivity to $\mathrm{Ni}^{2+}$ and mibefradil as Cav3 channels [65], we confirmed through an expression study in tsA-201 cells that $30 \mu \mathrm{M} \mathrm{Cd}{ }^{2+}$ is sufficient to block $\sim 90 \%$ of R-type $\mathrm{Ca}^{2+}$ current ( $n=5$; not shown). R-type $\mathrm{Ca}^{2+}$ channels then do not contribute to the LVA current measured at $-50 \mathrm{mV}$ in DCN cells, at least as tested burst cell. Insets show the effect of sequential perfusion of $\mathrm{Ca}^{2+}$ channel blockers, with no effect by $50 \mu \mathrm{M} \mathrm{Cd}^{2+}$ (blue trace) but a block by $300 \mu \mathrm{M} \mathrm{Ni}^{2+}$ (red trace) in both groups. Experiments shown in the insets included $1 \mathrm{mM} \mathrm{Cs}+$ in the bath. c The frequency and number of spikes in a rebound burst are highly correlated to the peak LVA current recorded in individual transient and weak burst cells. Burst frequencies are plotted as the increase above baseline tonic firing frequency. Modified from [7, 8]

in Fig. 3b. The data thus provide evidence that transient and weak burst phenotypes reflect a difference in the functional expression (amplitude) of T-type $\mathrm{Ca}^{2+}$ current at $-50 \mathrm{mV}$, a voltage near the threshold for LVA $\mathrm{Ca}^{2+}$ spikes and generation of the depolarization underlying the early phase of rebound firing.

Spike Afterpotentials Differ in Transient and Weak Burst Cells

Another means to control an excitatory membrane response is through differential expression of $\mathrm{K}^{+}$channels that offset depolarizations. To assess this possibility, we compared spike repolarization and afterpotentials in transient and weak burst neurons [8]. A comparison between several aspects of spike discharge revealed key differences in the relative amplitude and influence of the DAP and subsequent AHPs between transient and weak burst cells. The DAP was more effective in approaching spike threshold in transient burst cells, and AHPs were of larger amplitude in weak burst cells (Fig. 4a). These differences were substantial, with the average depth of the fAHP being twice as large in weak burst compared to transient burst cells 
a Tonic Spiking

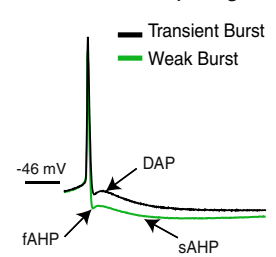

Rebound Spiking
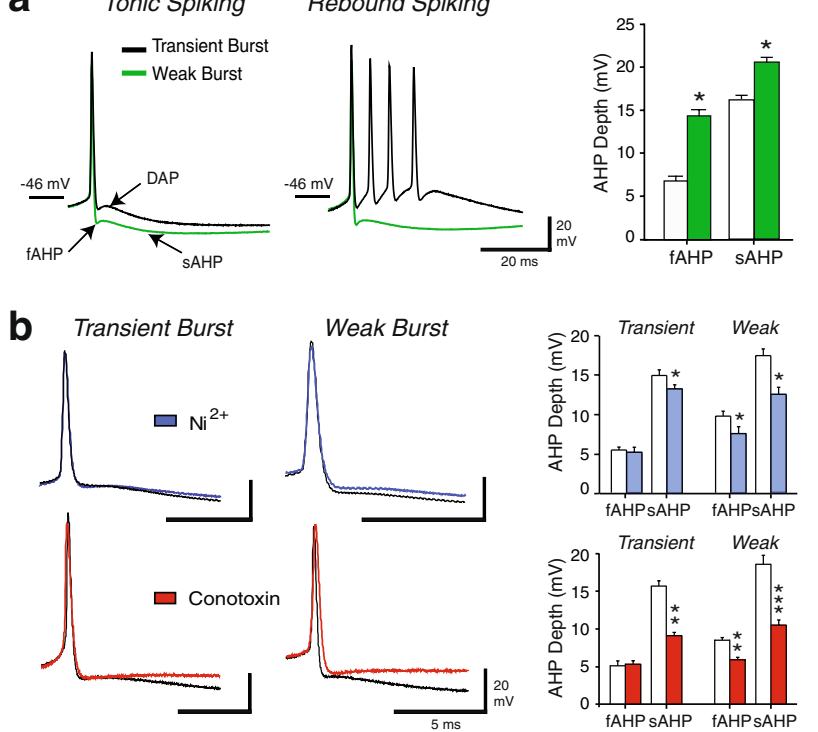

C
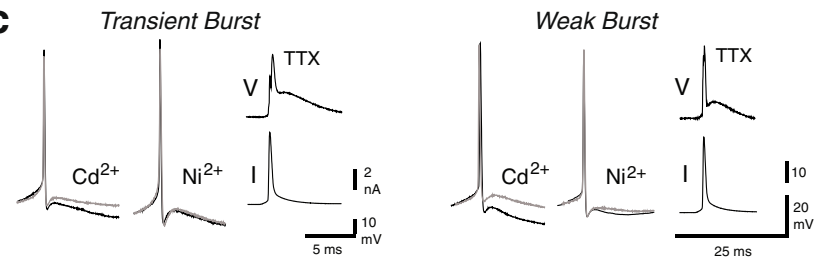

Fig. 4. Spike afterpotentials differ between transient burst and weak burst DCN neurons. a Representative superimposed spike traces from a transient burst cell (black trace) and weak burst cell (green trace) during tonic firing and rebound firing. Bar plots show the mean depth of the fAHP and sAHP of transient burst (white bars, $n=47$ ) and weak burst cells (green bars, $n=62$ ). b AHPs of transient and weak burst cells are differentially coupled to T-type and $\mathrm{N}$-type $\mathrm{Ca}^{2+}$ channel influx. Representative traces showing the effects of $\mathrm{Ni}^{2+}(300 \mu \mathrm{M}$, blue traces $)$ and $\omega$-conotoxin GVIA $(1 \mu \mathrm{M}$, red traces $)$. Bar plots of the mean depth of AHPs in control and drug conditions for transient burst $\left(n=7 \mathrm{Ni}^{2+} ; n=8\right.$ Conotoxin) and weak burst cells $\left(n=10 \mathrm{Ni}^{2+} ; n\right.$ $=8$ Conotoxin). $\mathbf{c}$ Spike DAPs are insensitive to $\mathrm{Ca}^{2+}$ and $\mathrm{Na}^{+}$channel blockers. Shown are superimposed traces before and after applying the general $\mathrm{Ca}^{2+}$ channel blockers $\mathrm{Ni}^{2+}(1 \mathrm{mM})$ or $\mathrm{Cd}^{2+}(50 \mu \mathrm{M}$, gray traces). Insets show that current injection that simulates a spike response can generate a DAP in the presence of $200 \mathrm{nM}$ TTX. Data presented in $\mathbf{a}$ and $\mathbf{c}$ were modified from [8]

(Fig. 4a). The peak of the DAP during tonic firing was also much farther from spike threshold in weak burst compared to transient burst cells (on average $-12.6 \mathrm{mV}$ in weak burst cells below spike threshold as compared to $-4.5 \mathrm{mV}$ for transient burst cells). Finally, the sAHP was significantly larger in weak burst compared to transient burst cells (20.5 mV in weak burst compared to $16.5 \mathrm{mV}$ in transient burst cells; Fig. 4a). The difference in sAHP amplitude was not as large as for the fAHP and DAP, potentially accounting for the relatively similar average rate of tonic firing in cells exhibiting either rebound phenotype (Table 1). Yet there is clearly a greater influence by the sAHP in weak burst cells during the immediate phase of rebound firing (Fig. 4a).

Previous investigations examined the distribution and pharmacology of $\mathrm{K}^{+}$channels in DCN cells, providing evidence for delayed rectifier (i.e., Kv3) and both small conductance (SK) and large conductance (BK) $\mathrm{Ca}^{2+}$ sensitive $\mathrm{K}^{+}$channels $\left(\mathrm{K}_{\mathrm{Ca}}\right)[1,2,4,5,9,41,42,45$, 6668]. We were interested in the fact that the degree of functional coupling between specific LVA or HVA $\mathrm{Ca}^{2+}$ channel subtypes and either SK or BK channels can differ between neurons [69-72]. We conducted tests to explore functional coupling between $\mathrm{Ca}^{2+}$ and $\mathrm{K}_{\mathrm{Ca}}$ channels in transient vs weak burst cells to determine the relative degree of control of excitability by AHPs. These experiments revealed that $\mathrm{Ca}^{2+}$ channel blockers had a larger effect on the AHPs of weak burst than transient burst cells, implying a greater degree of functional coupling between $\mathrm{Ca}^{2+}$ and $\mathrm{K}_{\mathrm{Ca}}$ channels in weak burst cells. However, many of these tests used cations $\left(\mathrm{Ni}^{2+}\right.$ or $\left.\mathrm{Cd}^{2+}\right)$ at concentrations that act as general blockers of $\mathrm{Ca}^{2+}$ channels. We now present new data to extend our analysis of the effects of $\mathrm{Ni}^{2+}$ at concentrations that are more selective as LVA $\mathrm{Ca}^{2+}$ channel blockers and for a specific $\mathrm{HVA} \mathrm{Ca}^{2+}$ channel blocker (shown in Fig. 4b). For space considerations, we only address the pharmacological sensitivity of spike afterpotentials during tonic activity. In transient burst cells, applying $300 \mu \mathrm{M} \mathrm{Ni}^{2+}$ had no effect on the fAHP, but slightly decreased the sAHP (Fig. $4 \mathrm{~b} ; n=7$ ). In weak burst cells, $\mathrm{Ni}^{2+}$ reduced both the fAHP and sAHP (Fig. $4 \mathrm{~b} ; n=$ 10). These effects were similar but of smaller magnitude than those obtained with mibefradil, which can be used as a relatively selective blocker of T-type $\mathrm{Ca}^{2+}$ channels at concentrations $<1 \mu \mathrm{M}[8,73]$. We can thus conclude that coupling between T-type $\mathrm{Ca}^{2+}$ channels and $\mathrm{K}_{\mathrm{Ca}}$ channels is different between transient and weak burst cells, but that $\mathrm{Ca}^{2+}$ influx through T-type $\mathrm{Ca}^{2+}$ channels is not sufficient to account for a large portion of the AHPs of DCN cells.

By comparison, a recent study showed that the rate of tonic discharge in large diameter DCN cells is highly influenced by $\mathrm{Ca}^{2+}$ influx through $\mathrm{N}$-type channels that are functionally coupled to $\mathrm{SK} \mathrm{K}^{+}$channels, although no distinction between rebound phenotypes was reported [41]. We now extend this analysis by applying $\omega$ conotoxin GVIA $(1 \mu \mathrm{M})$ by local pressure application to determine the effects on transient vs weak burst cells. To compare control and test AHPs, we chose action potentials that discharged from the same membrane voltage and outside of any substantial oscillatory depolarizations in the presence of $\omega$-conotoxin GVIA. These tests establish that in transient burst neurons, N-type $\mathrm{Ca}^{2+}$ channels exhibit functional coupling to only the SAHP, but in weak burst neurons to both the fAHP and sAHP (Fig. 4b). As shown in bar plots in Fig. 4b, the fAHP in weak burst cells was 
reduced by $\omega$-conotoxin GVIA $(n=8, p<0.01)$. An additional effect was noted on the rate of spike repolarization in weak burst cells (Fig. 4b), a result likely attributable to coupling between $\mathrm{N}$-type $\mathrm{Ca}^{2+}$ and $\mathrm{BK}$ channels [70]. The degree of block of the sAHP by $\omega$-conotoxin GVIA was significant in both cell types (transient burst, $n=8, p<0.01$; weak burst, $n=8, p<0.001$ ). These data confirm previous results, but further indicate that $\mathrm{N}$-type $\mathrm{Ca}^{2+}$ current and/or the coupling to $\mathrm{K}_{\mathrm{Ca}}$ channels that generate AHPs is more effective in weak burst cells.

We also examined the ionic basis for the DAP in DCN cells given its potential to contribute to interspike depolarizations and rebound discharge [8]. These experiments were revealing in showing that the DAP was completely resistant to TTX as well as the general $\mathrm{Ca}^{2+}$ channel blockers $\mathrm{Ni}^{2+}(1 \mathrm{mM})$ and $\mathrm{Cd}^{2+}(50 \mu \mathrm{M}$; Fig. $4 \mathrm{c})$. Given the ability to record a DAP in even $1 \mu \mathrm{M}$ TTX, we can further rule out the actions of a persistent $\mathrm{Na}^{+}$current or the resurgent $\mathrm{Na}^{+}$current found in these cells [4, 9, 74]. Interestingly, TTX application showed that the amplitude of the DAP was closely linked to that of the somatic spike [8]. Consistent with this would be a $\mathrm{Na}^{+}$-dependent but voltage, TTX-, and $\mathrm{Co}^{2+}$-insensitive current previously described for DCN cells during tonic firing [5]. Potential contributors to this current would be a $\mathrm{Ca}^{2+}$-activated non-selective cation channel (CAN) [75] or a $\mathrm{Ca}^{2+}$-induced $\mathrm{Ca}^{2+}$ release mechanism [76] that can contribute to DAPs in other cells. At this time, we can state that there was no affect of applying flufenamic acid on the DAP, a general blocker of CAN channels [8]. Therefore, the DAP does not require $\mathrm{Ni}^{2+}$-sensitive $\mathrm{Ca}^{2+}$ currents, TTX-sensitive $\mathrm{Na}^{+}$currents, or the $\mathrm{Ca}^{2+}$-activated currents we have tested to date. Another alternative to account for the DAP is that it is generated through a passive discharge of membrane capacitance following charging by the somatic $\mathrm{Na}^{+}$spike, as suggested by modeling studies of the closely aligned medial vestibular neurons [51]. The ability for this response to approach closer to spike threshold in transient burst cells may also reflect the smaller relative size of the fAHP in these cells.

\section{Synaptically Evoked Rebounds}

Most studies on rebound bursts have used current-evoked membrane hyperpolarizations. However, it will be important to extend these analyses to the more physiological situation of spike firing following synaptically evoked inhibition and determine whether the two burst phenotypes can be detected with this form of hyperpolarization. Several studies have reported that synaptically evoked inhibition will drive rebound increases in spike frequency in intracellular recordings in vitro $[2,9,10,13,15,16]$. It is worth considering that most intracellular recording studies in vitro routinely use some degree of constant current injection to stabilize membrane potential or tonic firing rate and thus potentially influence the probability of evoking rebound bursts following inhibitory synaptic trains. Examples of this include the more intense rebound frequency increases found when cells are held at relatively depolarized membrane potentials [2]. Recent studies have revisited the issue of the probability of synaptically evoking rebound increases or bursts in firing and the ability to distinguish transient and weak burst phenotypes.

Probability for Evoking Rebound Increases in Firing A recent study reported a low probability of detecting rebound responses both in vitro and in vivo using a $100-\mathrm{Hz}$, tenpulse train protocol to stimulate Purkinje cell inhibitory inputs [17]. A similarly low probability of evoking rebounds was encountered using photolytic release of caged GABA in vitro. The recordings were conducted primarily with on-cell recordings to avoid disrupting internal cell contents, and no distinctions were made between transient and weak burst phenotypes. The intensity of stimulation was set to generate a total pause in spike firing of $\sim 100-180 \mathrm{~ms}$ following the ten-pulse stimulation protocol as an estimate of a long period of GABAergic inhibition of spike discharge. The UV light intensity used to produce photolytic release of GABA in vitro was set to evoke a pause of 200-700 ms. Stimulation was applied to axons in the region of the cell in vitro or to the Purkinje cell layer in vivo. Using these stimulus parameters, the authors detected rebound firing increases in only $14-21 \%$ of cells in vitro (rat or mouse tissue slices) and only 10\% (2/20 cells) in vivo. In contrast, cells that were hyperpolarized using current injections to membrane potential levels below $E_{\mathrm{Cl}}$ in vitro generated rebound firing increases. The authors thus questioned whether the intrinsic membrane properties of DCN cells shown to underlie rebound frequency increases in previous studies (most of which employed current-evoked hyperpolarizations) can be extrapolated to the activity of cells inhibited by more physiological inputs.

This is an important question that was in turn assessed by Tadayonnejad et al. [16] who repeated these stimulus protocols for in vitro rat cerebellar slices. These authors used both on-cell and whole cell recordings and varying stimulus intensities to evoke synaptic inhibition with a $100-\mathrm{Hz}$, ten-pulse train delivered to the white matter carrying Purkinje cell axons. Cell output was examined in relation to IPSP amplitude, the duration of the post-stimulus pause, and the occurrence of rebound increases in firing as defined by statistical criteria. They found that the duration of the post-stimulus pause (referred to as first spike latency (FSL)) was inversely related to stimulus intensity and the frequency of rebound firing. Thus, stimulus intensities that 
evoked a post-stimulus FSL of up to a 136-ms duration (a value similar to that used in Alvina et al. [17]), indeed revealed a low probability for generating a rebound burst. At these intensities, only $~ 50 \%$ of transient and weak burst cells would exhibit statistically defined bursts. However, they also reported that the unusual inverse relationship between stimulus intensity and FSL means that a long FSL of the duration used by Alvina et al. [17] corresponds to a stimulus intensity only $\sim 20 \%$ of the maximal IPSP that can be evoked. Tadayonnejad et al. [16] found that moderate increases in stimulus intensity ( $\geq 40 \%$ of maximum intensity) reached a threshold that reliably evoked rebound bursts, with burst intensity increasing directly with the intensity of stimulation in either on-cell or whole cell configurations (Fig. 5a) [16]. They also found that a stimulus intensity set to $40 \%$ of maximum was within a physiological range in terms of IPSP amplitude and projected number of Purkinje cell axons activated. Thus, at $40 \%$ of maximum intensity, the mean IPSC amplitude was $183 \pm 24.2 \mathrm{pA}(n=11)$, reaching $\sim 300 \mathrm{pA}$ at maximum intensity (transient burst, $321 \pm 46 \mathrm{pA}, n=6$; weak burst, $299 \pm 39 \mathrm{pA}, n=7, p<0.05)$. A previous measure of the IPSC associated with minimal stimulation and nominal activation of single Purkinje cell axons was between 50 and $100 \mathrm{pA}$ [77]. The range of intensities over which these authors could evoke rebound bursts in vitro was thus well within the reported hundreds of Purkinje cell axons that terminate on individual DCN cells $[78,79]$. These results were also important in establishing that external and internal solutions used in that study define resting potentials and reversal potentials for $\mathrm{Cl}^{-}$ions appropriate for synaptic potentials to reach burst threshold.

The probability for recording synaptically evoked rebound increases in firing in vitro remains to be reported by other laboratories. A recent study reported that a period of synaptically evoked inhibition using a stimulus intensity estimated to activate 10-25 Purkinje cell axons $(100 \mathrm{~Hz}, 50$ pulses $)$ triggers a rebound increase in firing of $\sim 20 \mathrm{~Hz}$ beyond the initial tonic firing rate for $\sim 300 \mathrm{~ms}$ [10]. However, the probability of recording this activity was not specifically mentioned. An additional important note is that Tadayonnejad et al. [16] did not repeat these tests in vivo, leaving the probability for evoking rebound frequency increases in the fully intact circuit an open question.

Synaptically Evoked Rebounds in Transient and Weak Burst Cells Tadayonnejad et al. [16] also compared the response properties of transient and weak burst cells to current injection or inhibitory synaptic stimulation to determine if the two burst phenotypes could be detected after synaptic inhibition. An illustration of this is provided in Fig. $5 \mathrm{~b}$ in which the rebound frequencies evoked in transient and weak burst cells by a $100-\mathrm{Hz}$, ten-pulse inhibitory stimulus train is compared between one population recorded in whole cell configuration to another population recorded as single units in on-cell mode [16]. In this way, cells could be identified as exhibiting a transient or weak burst phenotype through direct current injection using the procedures described above (Fig. 1) before assessing their response to synaptic input. These authors found that a strength of inhibitory stimulation corresponding to $\sim 60 \%$ of the maximal evoked IPSC generated a statistically defined rebound burst response in all cells classified as either transient or weak burst cells. As expected, the maximal frequencies evoked by the inhibitory synaptic response were lower than those typically reported for direct current injection (cf. Fig. 1i). This derives from the fact that current pulse injections were applied for a longer period of time $(500 \mathrm{~ms})$ and from a level more hyperpolarized than $E_{\mathrm{Cl}}$. The synaptically evoked rebound frequencies for identified weak burst cells always fell below $30 \mathrm{~Hz}$ above the baseline firing rate (Fig. 5b). By comparison, synaptically evoked rebound frequencies for transient burst cells were distributed over a wider range of frequencies above $30 \mathrm{~Hz}$. These tests were repeated in a second population of cells recorded in on-cell mode to preserve internal cell contents with delivery of a similar train of synaptic stimuli and intensity adjusted to $60 \%$ of the maximum response. These experiments revealed weak burst and transient burst-like firing patterns (Fig. 5c) and statistically defined rebound frequency increases that fell over the same total range as those found for whole cell recordings (Fig. 5b). It was also confirmed through a series of sequential on-cell and then whole cell recordings in single cells that the distinction in synaptically evoked rebound frequencies for weak burst cells $(\leq 30 \mathrm{~Hz})$ vs transient burst cells $(>30 \mathrm{~Hz})$ were equivalent under either recording condition $(n=12$; Fig. $5 \mathrm{c}$ and Table 1) [16].

These results were important in establishing that the frequency of rebound bursts evoked by synaptic trains can be used to differentiate between transient and weak burst cells in unit recordings, at least in vitro. In contrast to current-evoked hyperpolarizations, the rebound frequency that can be used to distinguish between transient and weak burst cells following synaptic inhibition is $\sim 30 \mathrm{~Hz}$ above baseline tonic firing frequency. Therefore, both qualitative and quantitative comparisons of rebound responses evoked by direct current injection or synaptic inhibition in vitro reveal two rebound burst phenotypes among large diameter cells. A straightforward statistical means to define rebound bursts is also highly successful, at least given the low variability of tonic firing in DCN cells in vitro. The variability and high $\mathrm{CV}$ inherent to background firing rates of DCN cells in vivo [22, 38] may require more sophisticated methods. 
a

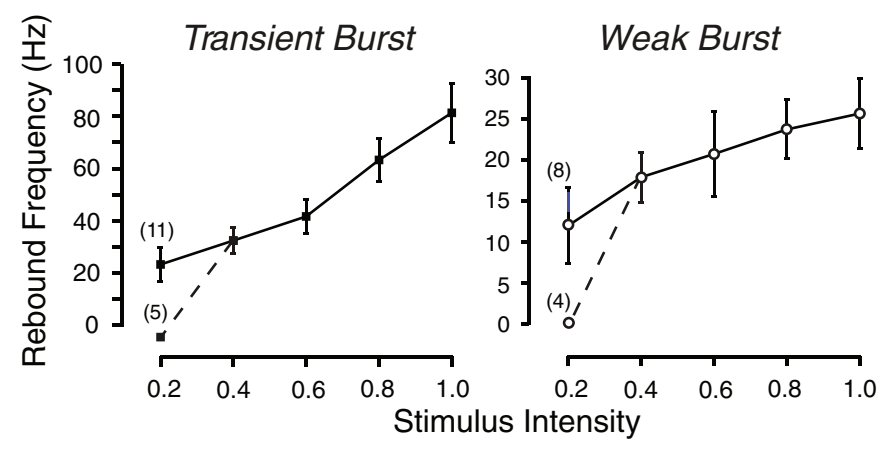

b

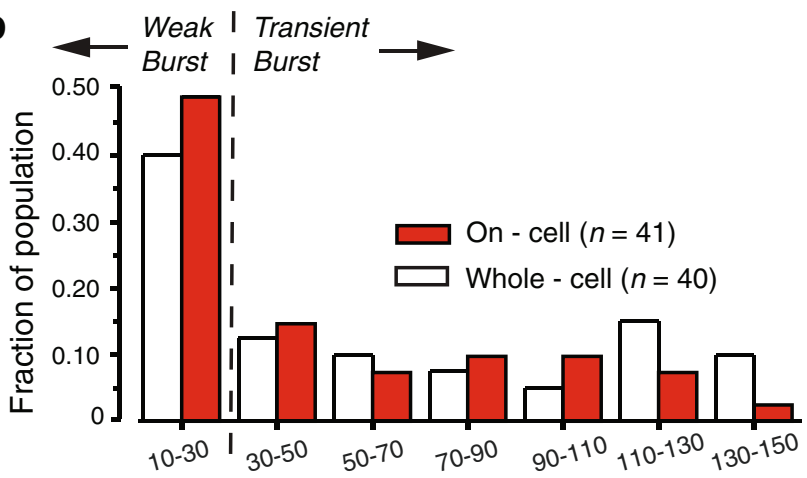

Synaptically evoked rebound frequency $(\mathrm{Hz})$

\section{Transient Burst On-cell recording}
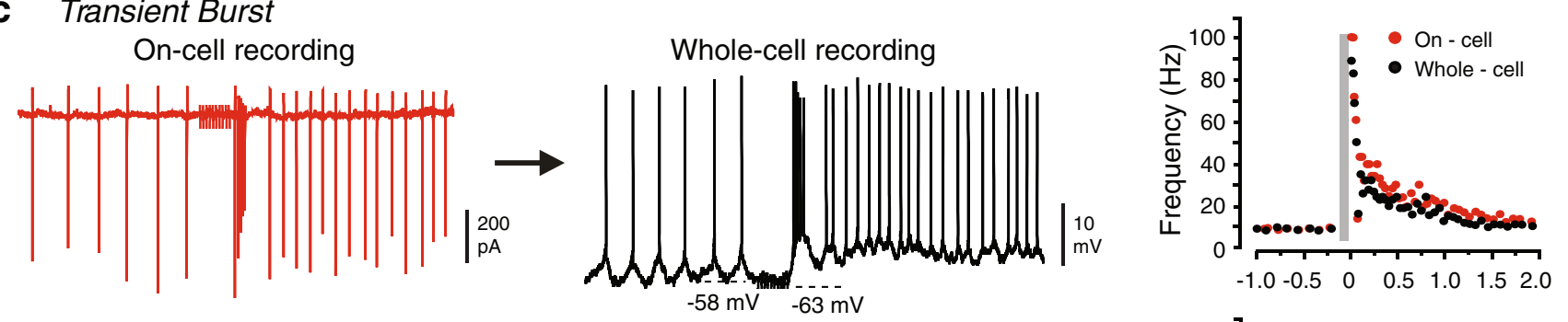

Weak Burst
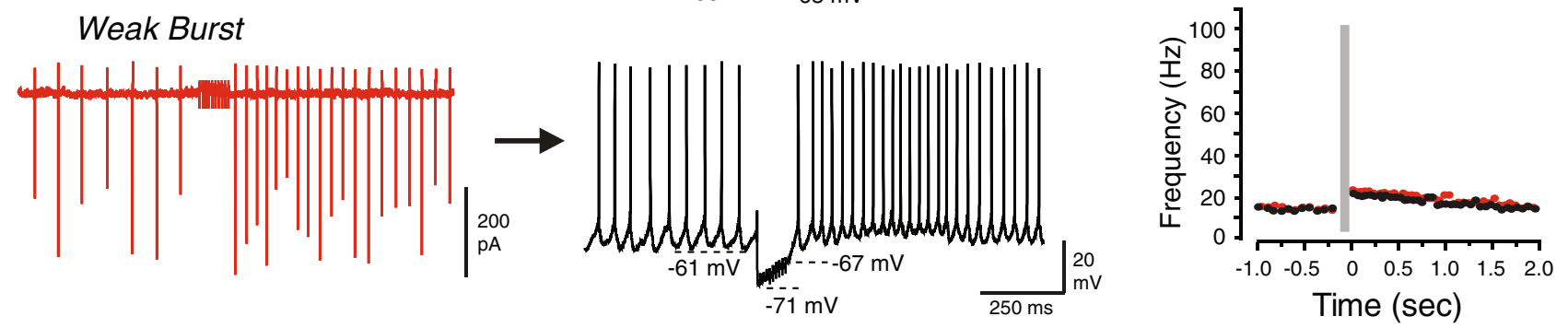

Fig. 5. Rebound bursts in transient and weak burst cells are evoked by inhibitory synaptic inputs. a Plots of the mean rebound frequency increase of transient $(n=16)$ and weak burst $(n=12)$ cells over a range of stimulus intensities (normalized to $100 \%$ of maximum) when recorded in on-cell mode. Dashed lines indicate that a subgroup of cells fail to exhibit rebound bursts at $20 \%$ of maximum intensity (number of samples indicated in brackets). b Bar plots of the maximum rebound burst frequencies in interpositus cells evoked by a ten-pulse, $100-\mathrm{Hz}$ stimulus to Purkinje cell afferents to evoke a series of IPSPs at $\sim 60 \%$ maximum intensity. White bars show the response of transient or weak burst phenotypes first identified through direct current injection in whole cell recordings (bin width $20 \mathrm{~Hz}, n=$
40) and red bars another population of cells recorded as single units in on-cell recording mode $(n=41)$. c Representative traces of transient and weak burst cells showing the effect of synaptic inhibitory stimulus trains when recorded first in on-cell mode (red traces) and following break-in to whole cell configuration (black traces). Stimulus artifacts are truncated. Plots of the corresponding instantaneous spike frequencies for these recordings are shown on the right (period of stimulation indicated by vertical gray bars). Plots were modified from [16]. Rebound frequencies shown in $\mathbf{a}$ and $\mathbf{b}$ represent increases beyond baseline tonic firing rates. The absolute membrane potentials at the trough of the AHP and during IPSPs are shown in $\mathbf{c}$

\section{Other Factors Governing Synaptically Evoked Rebound Responses}

It will now be important to more fully examine the nature of synaptic inhibition in DCN cells to determine if this form of membrane hyperpolarization recruits other factors than those invoked by direct current injection to promote rebound frequency increases. Purkinje cell synaptic terminals are interesting in exhibiting multiple release sites and uptake systems that help maintain the fidelity of transmission in the face of a pronounced frequency-dependent depression of IPSPs [77, 80-82].
The extent of membrane hyperpolarization or response of DCN cells might then rapidly change depending on the pattern, relative synchrony, or pauses in Purkinje cell input $[9,83,84]$. The influence of a change in the strength, frequency, and number of inhibitory stimuli on DCN cell firing has been demonstrated in in vitro preparations $[2,9$, $16,17,40,77,80]$. The importance of the synchrony of Purkinje cell inputs on the magnitude of IPSPs and subsequent increases in spike frequency has also been shown in in vivo studies [17, 19, 22, 25, 83, 84].

We were interested in determining if the ability to detect the two rebound phenotypes following synaptic activation 
could reflect a differential inhibitory influence on transient vs weak burst cells. To test this, we provide some unpublished observations on the IPSPs evoked by stimulating Purkinje cell afferents (Fig. 6a). These data reveal no difference in the IPSP or IPSC evoked in transient or weak burst cells in terms of amplitude or duration for a similar stimulus intensity ( $60 \%$ of the intensity required to evoke a maximum IPSC; Fig. 6a). The amplitude of the IPSP is also finely graded with the intensity of stimulation $[9,40,77]$, as confirmed for both transient and weak burst cells (Fig. 6b) [16]. The difference in rebound intensity between transient and weak burst cells then does not relate to any obvious difference in the magnitude of the single evoked IPSP. However, early work reported a difference in the efficacy of single evoked IPSPs compared to a brief train of stimuli in vitro $[2,9,13]$. We also found that rebound bursts in transient and weak burst cells are influenced by the number of repetitive stimuli delivered to Purkinje cell inputs, with a more intense rebound burst for 20 as compared to ten stimuli delivered at $100 \mathrm{~Hz}$ (Fig. 6c; as reported in [84]). Thus, for synaptic inhibitory trains initially set to $\sim 60 \%$ of the maximum amplitude IPSC, the rebound frequency of transient burst cells increased from $23 \pm 6.7 \mathrm{~Hz}$ for ten stimuli to $64 \pm 15.9 \mathrm{~Hz}$ for 20 stimuli $(n=13, p<0.05)$. For weak burst cells, the increase in rebound frequencies for 10-20 stimuli was $9.4 \pm 2.1$ to $22.8 \pm 3.65 \mathrm{~Hz}(n=12, p<0.05)$. Note that the increase in firing frequency extends well beyond the early phase and into the late phase of rebound firing (Fig. 6c).

These repetitive stimulus trains also serve to highlight some unique and important aspects of synaptic transmission between Purkinje cells and DCN cells that deserve further investigation. In particular, longer pulse trains reveal a frequency-dependent depression of transmitter release and IPSP amplitude (Fig. 6e) [77, 80-82, 85]. However, when comparing the relative shift in membrane potential during stimulus trains to the intensity of rebound discharge, it becomes apparent that DCN cells do not respond to repetitive inhibitory inputs in a manner entirely predicted for voltage-dependent postsynaptic channels. Thus, presenting a higher frequency, intensity, or number of stimuli results in a progressive shift in membrane potential to more depolarized levels through the stimulus train, at times even converging to an apparent common level of IPSC or membrane voltage at the soma [77, 80, 82, 85]. Despite this depolarizing shift during the train, higher stimulus intensities or additional stimulus pulses produce a more intense rebound response (see Figs. 5a and 6c). This would not normally be expected if the intensity of rebound was simply a function of the extent of recovery of T-type $\mathrm{Ca}^{2+}$ channels from inactivation during a preceding hyperpolarization. The data then suggest that some key factor(s) controlling the efficacy of Purkinje to DCN cell synaptic transmission remains to be identified. Among the a
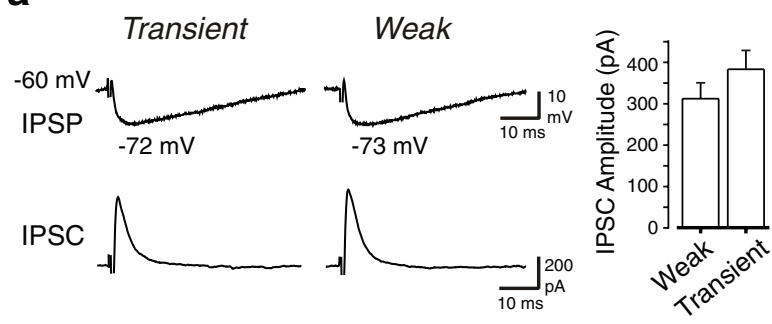

C Transient Burst 10 Stimuli
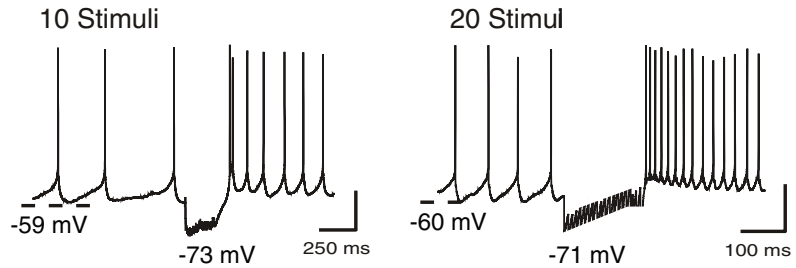

Fig. 6. Effects of Purkinje cell inhibitory synaptic input of transient and weak burst cells. a Comparison of single evoked IPSPs and associated IPSCs of representative transient and weak burst cells from a resting potential of $-60 \mathrm{mV}$. Stimulus intensity was set to $60 \%$ of a maximal IPSC. Plots of the mean amplitude and rate of decay of the IPSC for transient $(n=10)$ and weak burst $(n=10)$ cells reveal no significant difference in the single evoked response. b IPSPs are finely graded in amplitude with the intensity of stimulation. Stimulus intensities were normalized to that which evoked a maximum IPSC in each cell and IPSP amplitude to the response at 20\% maximum b
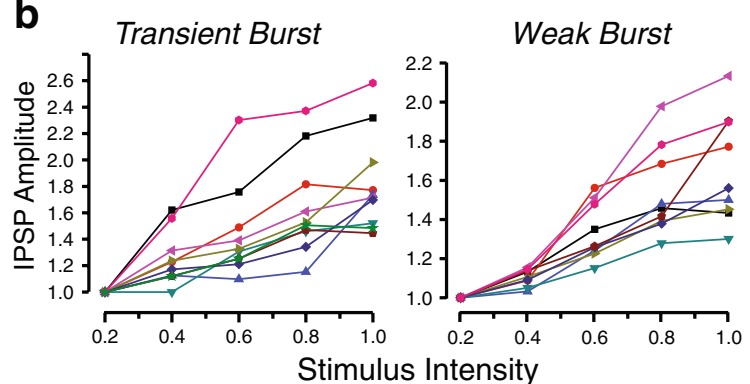

Weak Burst
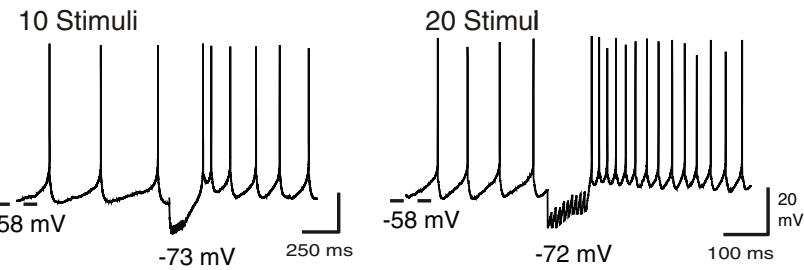

intensity. The response of several cells is shown superimposed. c Rebound burst intensity is affected by the number of presynaptic stimuli. Representative cells showing an increase in rebound intensity as the input is increased from 10 to 20 stimuli $(100 \mathrm{~Hz}, 60 \%$ maximum intensity, $p<0.05)$. Stimulus artifacts are truncated in $\mathbf{c}$. The absolute membrane potential at the trough of the AHP and during IPSP trains are shown in $\mathbf{a}$ and $\mathbf{c}$. Data in $\mathbf{a}$ and $\mathbf{b}$ is modified from [16] and in $\mathbf{c}$ from our recordings published in DeShutter and Steuber [84] 
first to note this was Aizenman and Linden [2] who recorded a long-lasting depolarization following a train of IPSPs delivered near the $\mathrm{Cl}^{-}$reversal potential. This depolarizing shift will reflect at least IPSP depression [77], but potentially also dendritic synaptic inputs, a shift in $\mathrm{Cl}^{-}$reversal potential, release and action of other transmitters, or the activation of a postsynaptic source of inward current that also contributes to the rebound response. Here, we briefly consider a few aspects of synaptic transmission in the DCN that might augment the depolarizing shift in membrane potential and the intensity of rebound frequency increases that occurs with repetitive stimulation.

First, an important feature of Purkinje to DCN cell transmission to consider is that Purkinje cell presynaptic terminals terminate in both the somatic and dendritic regions [34, 78, 86, 87]. In fact, there is evidence that at least some of the channels involved in generating rebound inward currents are located in dendritic as well as somatic regions $[5,10,15,44,61,62]$. The apparent discrepancy between net membrane potential by the end of a pulse train compared to the subsequent rebound response may then simply reflect the ability to monitor dendritic membrane potential shifts due to membrane filtering. Release of GABA from several presynaptic active sites per Purkinje cell bouton together with the position of glial transporters has also been proposed to promote substantial receptor occupancy within a region of $\sim 700 \mathrm{~nm}$ associated with each bouton. The net effect is to offset the extent of synaptic depression during high-frequency signaling and to preserve the independence of signaling by axon boutons [80, 81]. The relationship between the sites for bouton termination and ion channels involved in rebound increases in firing is unknown at this time. Aizenman and Linden [2] reported that a given level of membrane hyperpolarization at the soma was more effective at evoking rebound increases in firing when induced by synaptic activation as compared to somatic current injection. This result would suggest that the full extent of membrane hyperpolarizations induced by GABA release is not readily measured from a somatic recording site. The spillover process and GABA receptor occupancy inherent to Purkinje cell boutons may then effectively "clamp" regions of dendritic membrane to $E_{\mathrm{Cl}}$ at locations too distant to be accurately measured from the soma. If this occurs, it would signify some degree of recovery of LVA $\mathrm{Ca}^{2+}$ channels from inactivation in dendritic membrane and thus availability to subsequently contribute to rebound inward currents. Analyses of postsynaptic ion channels that govern rebound responses should then really include dendritic recordings instead of just the distant somatic recording site. However, since no dendritic recordings have been reported, the above interpretations must be considered speculative at this time.
Second, the shift in membrane potential during a stimulus train could indicate a difference in $E_{\mathrm{Cl}}$ between somatic and dendritic sites. In this regard, a shift in $E_{\mathrm{Cl}}$ through a differential expression of $\mathrm{Cl}^{-}$transporters is a well-known transition during development [88]. Although this remains a possibility, we are unaware of any evidence for a standing differential $E_{\mathrm{Cl}}$ between somatic and dendritic locations in adult neurons outside of specialized retinal synaptic connections $[89,90]$. It is also possible for $\mathrm{Cl}^{-}$gradients to collapse during repetitive stimulation, particularly when centered on small diameter dendrites, leading to a $\mathrm{HCO}^{-}$-mediated membrane depolarization through GABA receptors [91]. This is one possible outcome of the massive inhibitory drive provided by Purkinje cell axons that remains to be examined.

A third aspect worth considering is the potential to activate release of other transmitters during repetitive stimulation. This is particularly likely if one stimulates from within the boundaries of a nucleus where collateral axon branches or local networks can be directly activated. Yet, it must be recognized that this issue is not entirely circumvented even for stimulation sites outside of the DCN. One aspect of synaptic input that has received little attention to date is the potential for peptidergic or aminergic inputs to modify $\mathrm{DCN}$ cell activity [92-96]. $\mathrm{GABA}_{\mathrm{B}}$ receptors are also known to be expressed by DCN cells and can be activated by $\mathrm{GABA}_{\mathrm{B}}$ receptor agonists $[40,82$, 97]. However, attempts to activate these receptors through synaptic stimulation have consistently failed to identify a functional role [40, 82, 98]. Most of the small diameter cells in the DCN also label for glycine, with additional large diameter glycinergic cells labeled in the medial nucleus $[48,86]$. It is not likely that the effects of repetitive stimulation discussed here involve glycine receptor activation as the entire IPSP is blocked by picrotoxin, bicuculline, or SR-95531 [40, 77, 82]. Indeed, an analysis of glycinergic minis in DCN cells found no evidence for their presence during a period extending from P10 to P17 [99], the same range over which most patch recordings are made.

A fourth possibility for the depolarization underlying the rebound response is the activation of metabotropic receptors subsequent to release and spillover of glutamate from the excitatory collaterals of mossy fibers or climbing fibers ascending to cerebellar cortex. In fact, a study employing a glutamate transporter blocker described the activation of mGluR1 receptors in DCN cells during repetitive stimulation of mossy fiber inputs [100]. Although recordings of IPSPs are routinely performed in the presence of AMPA and NMDA receptor blockers, stimulation of climbing or mossy fibers could still result in sufficient release of glutamate to activate metabotropic receptors. This is important in that metabotropic receptor activation could contribute to both the steady membrane depolarization 
during the stimulus train as well as to the subsequent rebound depolarization and increase in spike frequency. To test this possibility, we repeated the ten-pulse, $100-\mathrm{Hz}$ stimulus protocol with the usual stimulus electrode placement dorsal and just outside the interpositus nucleus in the presence of picrotoxin $(50 \mu \mathrm{M})$ to block all inhibitory responses (Fig. 7a). We also stimulated from sites close to the recorded cell (within the nucleus) and from a ventral position to maximally activate any climbing fiber and mossy fiber afferents (Fig. 7a). Stimulation from either site under these conditions could evoke an EPSP typical for ionotropic glutamatergic responses [9, 32, 101]. Repetitive stimulation at $100-\mathrm{Hz}$ augmented EPSP amplitude during the stimulus train, but in all cases, this was followed by a rapid decay of spike frequency back to baseline levels within $\sim 100 \mathrm{~ms}$, with no evidence for a rebound depolarization or subsequent increase in spike frequency (Fig. 7b; $n=12$ transient, $n=11$ weak burst cells). To fully test for any metabotropic component, we repeated these stimuli in the presence of the mGluR1 receptor blocker JNJ16259685 $(50 \mathrm{nM})$ [102], which had no additional effect on the response following synaptic inhibition evoked from either stimulus site (Fig. 7b). Thus, the prominent metabotropic component recorded in Zhang and Linden [100] in the presence of a glutamate transporter blocker does not appear to contribute to rebound depolarizations under the conditions tested here. A second issue is the potential for metabotropic receptor activation to affect IPSPs in that Telgkamp and Raman [77] reported that the mGluR antagonist MCPG can produce a variable change in the amplitude of evoked IPSCs. In contrast, no effects by MCPG were reported on evoked trains of inhibitory inputs $[77,85]$. Metabotropic receptor activation may then be able to modulate IPSPs, but does not appear to contribute to the postsynaptic rebound depolarization.

\section{Measurement of Internal $\mathrm{Ca}^{2+}$ Changes}

Previous work in the slice preparation monitored the change in $[\mathrm{Ca}]_{i}$ at the somatic or dendritic level of DCN cells during the activation of LVA or HVA $\mathrm{Ca}^{2+}$ current or $\mathrm{Ca}^{2+}$ spikes [10, 13, 15, 44, 62]. These studies used depolarizing steps from a negative holding potential and measured the change in $[\mathrm{Ca}]_{\mathrm{i}}$ using $\mathrm{Ca}^{2+}$-sensitive indicators. Changes in $\mathrm{Ca}^{2+}$ fluorescence consistent with LVA and HVA currents could be recorded in soma and dendrites in response to step commands, but with a greater contribution by $\mathrm{HVA} \mathrm{Ca}^{2+}$-induced fluorescence at the soma and increasing LVA contribution with distance along the dendrites [44, 62]. Using trains of inhibitory synaptic input, Zhang et al. [15] further recorded the largest $\mathrm{Ca}^{2+}$ fluorescent transient in distal dendrites $(>100 \mu \mathrm{M}$ from the soma) during the rebound burst. Recent work examined the ability for membrane hyperpolarizations evoked by either direct current injection or synaptic input to alter $[\mathrm{Ca}]_{\mathrm{i}}$ levels and provides an entirely new outlook on $[\mathrm{Ca}]_{i}$ changes accompanying rebound bursts $[10,61]$. First, they found that when DCN cells were hyperpolarized to stop

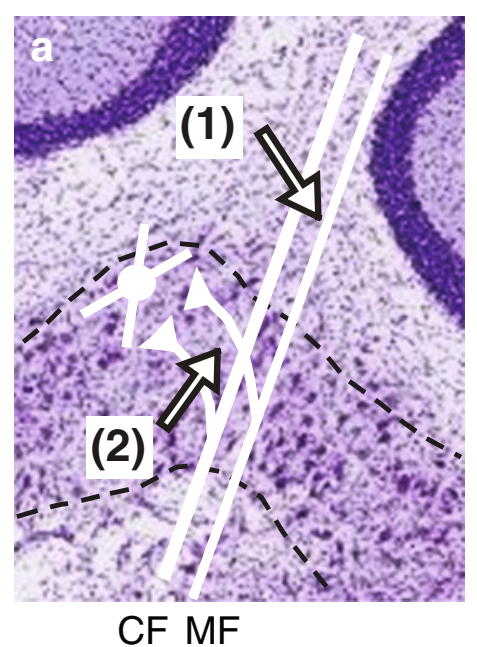

b
(1)

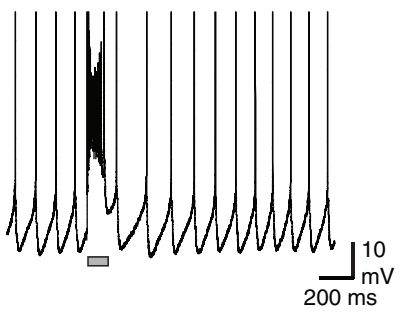

(2)

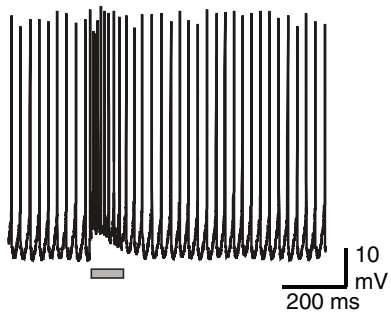

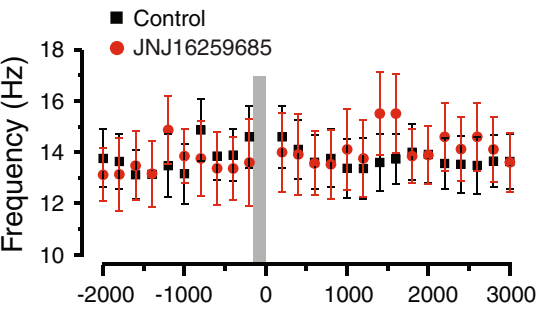

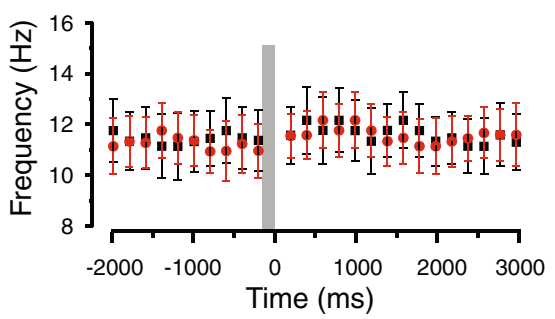

Fig. 7. Repetitive stimulation does not recruit metabotropic glutamate receptor depolarizations. a On the left is a schematic diagram of climbing fiber $(C F)$ and mossy fiber $(M F)$ afferents with excitatory collaterals to DCN cells of the interpositus nucleus (cresyl violetstained sagittal slice). Numbers and arrows denote the point of stimulation in a slice. All recordings were performed in $50 \mu \mathrm{M}$ picrotoxin. EPSPs were evoked from a stimulation site dorsal and outside of the nucleus $(1)$ or from a site ventral and closer to recorded cells within the nucleus (2). b On the left are representative recordings from two different transient burst cells in response to ten-pulse, 100$\mathrm{Hz}$ stimulus trains (horizontal gray bars) from the two stimulus sites. On the right plots of the mean spike frequency before and after stimulus trains (demarked by vertical gray bars) reveal no evidence for a rebound frequency increase either in control conditions or in the presence of the mGluR1 receptor blocker JNJ16259685 (50 nM, $n=12$ transient, $n=11$ weak burst) 
spike firing, the level of dendritic $[\mathrm{Ca}]_{\mathrm{i}}$ decreased by $\sim 22 \%$ for $500-\mathrm{ms}$ steps to $-80 \mathrm{mV}$, a response that can be attributed to at least the loss of spike firing. Upon release from hyperpolarization and during rebound firing, the relative fluorescence rose above the levels observed during initial tonic firing, but typically only for current-evoked hyperpolarizations below the $E_{\mathrm{Cl}}$ of $-75 \mathrm{mV}$ [10]. The study of Zheng and Raman [10] was also important in directly showing that the late phase of $[\mathrm{Ca}]_{\mathrm{i}}$ increase is sensitive to blockers of all the HVA $\mathrm{Ca}^{2+}$ channel isoforms (L-, N-, P/Q-, and R-type), emphasizing the diversity of currents that can contribute to rebound firing.

If T-type currents are activated and contribute to the early phase of the rebound burst, one would anticipate an overshoot in internal $\mathrm{Ca}^{2+}$ fluorescence during this time frame. Surprisingly, there was a lack of an early postinhibitory overshoot in $\mathrm{Ca}^{2+}$-induced fluorescence above the original baseline levels. This is particularly the case following a train of evoked IPSPs (Fig. 4c of [10]) as this stimulus was previously shown to be more effective at triggering rebound firing than an equivalent level of current-evoked hyperpolarization [2]. The lack of this response was not due to detection capabilities since the dyes and system used to detect $\mathrm{Ca}^{2+}$ concentration changes had a high enough temporal resolution to signal changes in fluorescence associated with single spikes at the somatic or dendritic level [10]. Zheng and Raman [10] further tested the degree of recovery of T-type currents under voltage clamp following step hyperpolarizing commands of different magnitude and duration (100-500 ms), including those relevant to physiological inputs (IPSPs). They found that steps to $-70 \mathrm{mV}$ for even $500 \mathrm{~ms}$ allowed only $\sim 9 \%$ of the available T-type current to recover from the inactivation associated with a holding potential of $-60 \mathrm{mV}$. Importantly, this level of hyperpolarization is comparable to the membrane potential attained during a train of evoked IPSPs $(100 \mathrm{~Hz}, 50$ pulses), particularly given the depolarizing shift in membrane potential to a value even less than the reversal potential of $\mathrm{Cl}^{-}(-67$ to $-70 \mathrm{mV})$ [77, 80, 103]. The authors thus interpret the data to indicate little recovery of T-type current during physiological inputs and thus little, if any, contribution of T-type $\mathrm{Ca}^{2+}$ currents to the rebound response evoked by Purkinje cell inhibition. This new interpretation is interesting and represents a significant shift from previous expectations of the role for T-type $\mathrm{Ca}^{2+}$ currents in rebound discharge, with the potential to redirect much of the work in this area.

Nevertheless, inspection of the data currently available suggests that final dismissal of T-type currents as a contributing factor to rebound responses requires a limited number of additional tests. Data that would support a potential contribution by T-type current to the early phase of rebound firing is the very high correlation between $\mathrm{T}$ - type current evoked at $-50 \mathrm{mV}$ and both the number and frequency of spikes during the initial rebound (Fig. 3c) [8]. Although these correlations were established using a prestep potential to $-90 \mathrm{mV}$ (a value below $E_{\mathrm{Cl}}$ ), the strength of this correlation $(r>0.92)$ indicates that under some conditions, T-type current can have a significant role in determining burst output and phenotype. This was further supported by the study of Alvina et al. [52] who reduced rebound responses with blockers of T-type $\mathrm{Ca}^{2+}$ channels. The ability to detect both phenotypes following inhibitory synaptic activation is at least suggestive that similar mechanisms might be involved, although this has not yet been directly tested.

It is important to note that all measurements of $\mathrm{Ca}^{2+}$ flux following synaptically evoked inhibition in intact DCN cells in Zheng and Raman [10] were of necessity indirect in terms of relative fluorescence associated with a change in $[\mathrm{Ca}]_{\mathrm{i}}$. It has been reported that the ability to detect a change in $[\mathrm{Ca}]_{\mathrm{i}}$ in DCN cells is less likely during a $\mathrm{LVA} \mathrm{Ca}^{2+}$ spike or subthreshold rebound depolarization than during $\mathrm{Na}^{+}$ spikes [13, 44]. It has further been shown that as little as $20 \%$ of the maximum T-type $\mathrm{Ca}^{2+}$ current available in thalamic neurons is sufficient to support a rebound burst response [104]. It is thus possible that the fluorescent dyes used are unable to signal the small change in $[\mathrm{Ca}]_{\mathrm{i}}$ that could accompany an active membrane rebound response. On the other hand, it is interesting that the rate of rise of $[\mathrm{Ca}]_{\mathrm{i}}$ in Zheng and Raman [10] is faster during the immediate rebound response than during the onset of the membrane hyperpolarization. Although this is expected for an abrupt increase in spike firing at the end of a pulse compared to the loss of spike firing at the onset of a hyperpolarization, the change in $[\mathrm{Ca}]_{\mathrm{i}}$ that reflects $\mathrm{T}$-type current may be hidden here. In support of this, currentevoked membrane hyperpolarizations to as low as $-120 \mathrm{mV}$ also do not show an overshoot in the fluorescent signal during the initial $50-100 \mathrm{~ms}$ following the step command (Fig. 3c of [10]), even though T-type currents are present during this time frame under voltage clamp (Fig. 3b) $[8,10,32]$. It would be interesting to analyze the rate of change in fluorescence after inhibition is removed to determine if any transients are present during the initial $100 \mathrm{~ms}$ when T-type $\mathrm{Ca}^{2+}$ influx occurs. Finally, continued availability of $9 \%$ of T-type current following physiologically relevant hyperpolarizations is within a range one might expect for a window current that will exist within the range of overlap of T-type channel activation and inactivation profiles. Key tests that remain to be conducted are to directly measure T-type currents under voltage clamp following a train of inhibitory synaptic inputs to determine if any current can exhibit recovery and then to test whether any such current might be sufficient to alter spike firing. If these tests were to fail to show the 
recovery of T-type $\mathrm{Ca}^{2+}$ current at a level sufficient to contribute to an increase in spike frequency, then the potential role for T-type channels in DCN cell physiology will certainly need reevaluation.

\section{Discussion}

The present review summarizes the data obtained on rebound frequency increases in DCN cells in response to membrane hyperpolarizations evoked by either direct current injection or stimulation of Purkinje cell inhibitory inputs since the first in vitro recordings in the 1980s. We further examine the evidence for distinct phenotypes of rebound burst among large diameter cells, at least according to the properties and ionic basis for the early phase of rebound frequency increases. Finally, we summarize recent data that raise questions as to the probability for synaptic inputs to evoke rebounds and their underlying ionic basis.

\section{Transient vs Weak Burst Cells in the DCN}

We and others have provided evidence for the existence of different categories of large diameter cells in the DCN based on the phenotypes of spike firing in vitro $[7,8,12$, $15,45]$. A relatively recent classification into a transient and weak burst phenotype was proposed due to the prevalence of cells encountered in vitro that express either high frequencies of rebound in conjunction with an initial transient component (transient burst) or lower rebound frequencies without a transient component (weak burst). As summarized here, the two phenotypes have been shown to arise from a different complement or functional expression of membrane properties, including those arising from LVA $\mathrm{Ca}^{2+}$ current, a DAP, and the relative coupling between $\mathrm{Ca}^{2+}$ channels and $\mathrm{K}_{\mathrm{Ca}}$-mediated AHPs $[7,8,16]$. Thus, in transient burst cells, a higher functional expression level of Cav3 $\mathrm{Ca}^{2+}$ current and a DAP can contribute to a currentevoked rebound burst. In weak burst cells, $\mathrm{Ca}^{2+}$ and $\mathrm{K}^{+}$ channels (particularly $\mathrm{N}$-type $\mathrm{Ca}^{2+}$ channels) are more effective in generating AHPs that will further reduce the ability for a lower expression of Cav3 $\mathrm{Ca}^{2+}$ current to generate a rebound burst. Both burst phenotypes can be detected following hyperpolarizing current injections or synaptic inhibition delivered from resting membrane potentials and for even moderate stimulation of Purkinje cell inputs.

It is important to consider whether the different firing patterns of DCN cells reflect two distinct populations of cells or instead either extreme of a continuum of membrane properties in the same population (as has been debated for cells of the medial vestibular nuclei [105]. On the one hand, transient and weak burst phenotypes are similar in terms of several membrane properties and synaptic activation, exhibiting a similar range of input resistance, spike amplitude and duration, tonic firing rates, gain, and evoked IPSPs. We can also recognize $\sim 17 \%$ overlap between defined transient and weak burst cells in terms of rebound firing rates in the $\sim 50-$ to $100-\mathrm{Hz}$ range (Fig. 1i). At this point, cells in this frequency range are grouped on a comparatively subjective basis according to the presence or absence of a transient burst component. Exceptions can further be found where a cell without a transient burst component (normally classified as a weak burst cell) can generate rebound frequencies at rates even slightly higher than $100 \mathrm{~Hz}$. We thus recognize that our current definition of burst phenotypes is not absolute and will evolve as more information becomes available. This is particularly the case for the wide range of rebound frequencies we currently group into the broad category of "weak burst" cells [8]. In contrast, the cluster analysis of rebound frequencies generated to the same hyperpolarizing stimulus suggests the presence of two groups of cells that differ in rebound discharge capability.

As summarized in Figs. 2, 3, and 4, the ionic analyses conducted to date reveal fundamental differences in ion channel availability and interactions that distinguish cells exhibiting either burst phenotype. Given this, the potential that rebound responses represent a continuum of spike output would require a change in channel expression or interaction. This is not out of the question given that Cav3 channels are increasingly recognized as targets for modulation $[59,106]$ and that the density of at least $\mathrm{Cav} 3.2 \mathrm{Ca}^{2+}$ channels can change with epileptic activity [107]. A change in $\mathrm{K}^{+}$channel density or voltage dependence could also shift the gain of a cell and thus rebound frequency. In support of this possibility, Zhang et al. [15] reported that repetitive bursts of EPSPs can shift the mode of currentevoked firing from burst to tonic in a subset of DCN cells. Delivering a burst of IPSPs also triggered changes in Ri and intrinsic excitability to depolarizing current, but any effects on the rebound properties or mode of firing were not specified. The extent to which these findings apply to transient or weak burst cells is currently unknown, but if this were to occur, it would open up interesting possibilities for state-dependent shifts in rebound spike output. Yet, even if this degree of plasticity should identify a continuum of firing properties, we feel at this point that the substantial differences in ion channels and spike output that exist between DCN cells warrant the distinction of two burst phenotypes.

We currently have no evidence to support the possibility that different burst phenotypes reflect populations of cells that differ in terms of transmitter content or projection patterns $[47-49,108]$. Rather, we know that transient burst discharge can be found in large diameter $\mathrm{GAD}(+)$ or $\mathrm{GAD}$ 
(-) cells and weak burst output in $\mathrm{GAD}(-)$ cells [7]. Although evoked IPSPs appear very similar in cells with either burst phenotype, we have no information as to whether they might receive differential projections from ascending excitatory inputs (mossy and climbing fiber collaterals), Purkinje cell inhibitory inputs, local inputs, or aminergic inputs that might be capable of driving different functional outputs [86, 87, 92, 99, 108].

Role of T-Type $\mathrm{Ca}^{2+}$ Currents in Generating a Rebound Increase in Spike Frequency

The extent to which T-type $\mathrm{Ca}^{2+}$ currents contribute to rebound frequency increases following membrane hyperpolarizations has gone from early conclusions regarding its role based on current-clamp recordings and pharmacology in vitro to additional apparent evidence through voltageclamp analyses (step commands) and $\mathrm{Ca}^{2+}$ fluorescent measurements to an interesting reassessment in the past year based on measurements with improved fluorescent $\mathrm{Ca}^{2+}$-sensitive dyes. Central to this discussion is a recent $\mathrm{Ca}^{2+}$ imaging study that led to the conclusion that relatively minor shifts in membrane potential to near $E_{\mathrm{Cl}}$ during synaptic inhibition were not capable of promoting sufficient recovery of T-type channels from inactivation to participate in the immediate phase of rebound firing [10]. This is seminal work that challenges long-standing interpretations regarding the mechanism for rebound firing, providing impetus for a close reexamination of the role for T-type currents. As pointed out by Zheng and Raman [10], there are reasons to question the degree to which T-type currents might contribute to rebound firing in the context of physiological levels of hyperpolarization. At this time, the current authors feel that a final determination on this point is at hand, pending the outcome of a limited number of additional tests. These are specifically voltage-clamp recordings of T-type current following synaptically evoked hyperpolarizations, and consideration of the extent to which any T-type current that might be evoked can affect spike firing in these cells.

A particularly important result in the $\mathrm{Ca}^{2+}$ imaging experiments of Raman and colleagues [10, 61] is the decrease in $[\mathrm{Ca}]_{\mathrm{i}}$ observed at the soma and dendrites during trains of synaptic inhibition. As suggested by Zheng and Raman [10], these findings likely have direct relevance to the ability for $\mathrm{Ca}^{2+}$-dependent AHPs to regulate spike frequency according to the level of $[\mathrm{Ca}]_{\mathrm{i}}$. Thus, a lower $[\mathrm{Ca}]_{\mathrm{i}}$ induced by a membrane hyperpolarization may decrease AHP amplitudes immediately following a hyperpolarization, thereby increasing spike frequency until $[\mathrm{Ca}]_{i}$ recovers to control levels after the resumption of spike discharge. A decrease in AHP amplitudes is in fact found in DCN cells during the early phase of rebound bursts [8], but the underlying source of this effect was hard to identify given the coincident activation of inward currents. It is thus very likely that the decrease in $[\mathrm{Ca}]_{\mathrm{i}}$ that persists for some time after the end of a membrane hyperpolarization $[10,61]$ is a second and important factor determining an increase in rebound firing frequency.

\section{Probability for Evoking Rebound Bursts Following} Inhibitory Synaptic Inputs

Another development in the field has been the recent presentation of data that draws into question the probability of evoking rebound bursts either in vitro or in vivo following synaptic inhibition [17]. This work is also important in questioning long-standing views of the ability for intrinsic membrane properties of DCN cells to contribute to rebound firing and as a reminder of the importance of focusing work in vitro on synaptically evoked responses. As discussed above, another laboratory obtained the same result as Alvina et al. [17] using equivalent levels of stimulation [16]. However, they also provided evidence that inhibitory inputs delivered at slightly higher intensities, but within the realm of physiologically relevant numbers of Purkinje cell axons, reliably evoked rebound bursts at least in vitro. A repetition of these tests by other labs to determine the extent to which others encounter either a low or high probability of evoking rebounds with inhibitory inputs will help resolve this issue. In particular, similar tests to those of Alvina et al. [17] for in vivo recordings await to be reported, but will be important in further delineating the capability for rebound firing to contribute to cerebellar output in the intact system.

\section{Evidence for Distinct Burst Phenotypes In Vitro}

It is useful to compare the recordings in previous publications to determine if rebound burst properties consistent with our definition of transient and weak burst output can be recognized. In making these comparisons, it is important to note that early recordings were made with microelectrodes as compared to patch recordings $[2,9,13$, 46] and thus have significantly different Ri values. Llinas and Mulethaler [9] further used an intact cerebellar/ brainstem preparation that has potential for reverberatory circuit activity or the influence of oscillatory input in inferior olivary cells. The patch recordings in Czubayko et al. [1] are closer to our recording configuration, but included $5 \mathrm{mM}$ EGTA in the pipette, which we find promotes oscillatory discharge when SK channel function is compromised. Another factor that can substantially affect cell excitability is the level of external $\mathrm{K}^{+}$concentration. This factor has varied considerably between the different labs conducting in vitro recordings of spike responses, with 
values between $2.5-2.7 \mathrm{mM}[1,17,40], 3.25-3.5 \mathrm{mM}[7$, $10]$, or $4.0-5.0 \mathrm{mM}[3,5,12,13,15,39,46]$. It would be of interest to standardize this factor and other aspects of recording solutions to values closest to physiological levels to reduce variability in results [109].

Comparisons of recordings from other studies indicate that for Aizenman et al. [13], we would identify a transient burst-like frequency response following their delivery of a train of IPSPs ( $\sim 83 \mathrm{~Hz}$, their Fig. 3a) and a weak burst-like response to a current-evoked hyperpolarization $(\sim 40 \mathrm{~Hz}$, their Fig. 5a). Similarly, the synaptically evoked responses for two cells in Fig. 6a, b of Aizenman and Linden [2] is similar to the pattern of firing in our recordings of transient and weak burst cells shown here in Fig. 5c. The difference would be a shorter burst duration in their results, but this could be due to a lower Ri with microelectrode recordings. Also, as pointed out in their Fig. 6b, tonic hyperpolarization decreases the duration of rebound firing, which is consistent with these differences in that all of our cells were tonically firing from a resting of approx. $-60 \mathrm{mV}$ (trough of AHPs) when tested. In Pugh and Raman [61], the rebound bursts evoked following current-evoked hyperpolarizations exhibit frequencies consistent with our definition of weak burst cells $(\sim 100 \mathrm{~Hz}$, their Fig. 2a) or an initial high-frequency component we would identify as a transient burst cell (their Fig. 4a). Similarly, in response to hyperpolarizing current pulses in Zheng and Raman [10], a transient-like burst appears to be recorded in their Fig. $4 \mathrm{~b}(\sim 160 \mathrm{~Hz})$ and Fig. 8c $(\sim 200 \mathrm{~Hz})$ and weak burst-like responses in their Fig. 4c $(\sim 80 \mathrm{~Hz})$ and Fig. 8a $(\sim 120 \mathrm{~Hz})$. Most recently, Hurlock et al. [45] reported a distinction between strong and weak burst properties in mouse DCN cells maintained in vitro. The firing patterns for cells shown in their Fig. $3 \mathrm{f}-\mathrm{i}$ bear many similarities to the rebound frequency increases we find between transient and weak burst cells, although their recordings indicate a greater degree of spike accommodation than we characteristically see in rat DCN. It is more difficult to compare recordings of rebound responses in Czubayko et al. [1] or that of Llinas and Mulethaler [9] and Mouginot and Gawhiler [40] given differences in their patch recording solutions and preparations.

\section{Physiological Relevance of Rebound Bursts}

Burst discharge has been proposed to enhance the fidelity of cell-to-cell synaptic transmission and function in neural coding of inputs $[110,111]$. Although the incidence and role for burst discharge has been debated in several systems, bursts have now been recorded in response to sensory input in awake and unanesthetized animals [112117]. The role for burst discharge in feature detection has been convincingly demonstrated in sensory $[111,115,118$, 119] and thalamic neurons [114, 117]. Yet even the potential to record rebound bursts in DCN cells in the live animal remains a source of debate, with the functional significance of this activity relatively unknown. Although a full consideration of this matter is beyond the scope of this review, there are records in the literature that are highly suggestive that this activity can be a component part of the DCN cell response under certain conditions.

The potential for rebound bursts to contribute to DCN cell output in vivo has perhaps been best illustrated in terms of directly evoked inhibitory responses and in natural activity during eye movements. Early intracellular recordings from cat interpositus neurons in vivo showed that electrical stimulation of either the inferior olive or lateral reticular nucleus evoked an intensity-dependent EPSPIPSP sequence that was followed by a depolarization and spike frequency increase over $\sim 50 \mathrm{~ms}[19,20,26]$. Recent work using patch recordings in vivo have begun to report similar findings with respect to DCN rebound bursts evoked by inferior olivary stimulation [120].

Work performed in the area of rapid eye movements or the reflex eyeblink response provides further evidence for distinct firing patterns within the DCN cell population and for a rapid transition to high-frequency firing following a pause in spike firing. In particular, a study of rat interpositus neurons during reflex eyeblinks provides a direct potential comparison to the transient and weak burst phenotypes we record in vitro. These authors found that the response of rat DCN cells during the eyeblink reflex could be distinguished according to burst or pause firing patterns [25]. Pause cells were the most numerous (91/131) and tend to pause their discharge just prior to eyelid opening. Burst neurons (40/131) increased their firing rate up to $120 \mathrm{~Hz}$ approximately in relation to the orbicularis EMG. Intriguingly, our ratio of weak to transient burst cell recordings in the interpositus nucleus of the slice preparation is 2.12 [8], a value not unlike the ratio of 2.27 for pause to burst cells in vivo [25]. Thus, the prevalence and differential responsiveness of two cell types in the rat interpositus during a behavioral response in vivo at least draws interesting parallels to the activity we record in vitro in this nucleus. There are further potential comparisons to pause and burst firing cells localized to the cat anterior interpositus nucleus in relation to eyeblink conditioning (reviewed in $[31,121]$ ). Nevertheless, we find that both burst phenotypes are readily detected in vitro in medial and lateral nuclei of the rat $\mathrm{DCN}$, suggesting that these differences are not just inherent to divisions of the interpositus nucleus. In another series of studies, Ohtsuka et al. examined saccadic eye movements in the fastigial oculomotor region of monkeys and recorded the activity of mossy fiber afferents, Purkinje cells, and DCN cells $[27,122,123]$. Correlations between the time of Purkinje cell firing, the pause in DCN cell firing, and the subsequent increase in DCN cell firing were all highly 
suggestive of an IPSP-evoked rebound discharge. However, at this time, an unequivocal association between the intrinsic properties that drive rebound bursts in DCN cells in vitro to the increases in firing rate observed following a period of inhibition in vivo has not yet been attained. Indeed, the potential for conjunctively activated excitatory inputs (climbing or mossy fibers) to contribute to a frequency increase following a pause in DCN cell firing must be carefully considered [22, 25, 124]. For instance, a significant portion of the increase in DCN cell firing following a pause in firing (as part of the reflex eye blink response) persisted after local ejection of gabazine to block GABAergic responses [25].

In summary, the ability for DCN cells to exhibit rebound discharge is well tailored to the need to encode the end result of cerebellar cortical processing that presents itself in the form of Purkinje cell inhibitory input. Our knowledge of the factors that control rebound discharge in DCN neurons has increased tremendously through the use of a wide range of in vitro methodologies. The finding that at least large diameter DCN cells exhibit different rebound properties in vitro goes one step further in potentially identifying the ionic basis for the different firing patterns that DCN cells exhibit in relation to behavioral inputs in vivo.

Acknowledgments We gratefully acknowledge M. Kruskic and L. Chen for expert technical assistance, B.E. McKay (Wilfrid Laurier University) for assistance in statistical analyses, and G.W. Zamponi for collaborative contributions to the work reviewed here. Supported by grants from the Canadian Institute of Health Research (CIHR) to RWT and GWZ and studentship support through the Alberta Heritage Foundation for Medical Research (AHFMR) (WHM, RT, DA, MM, KJ), CIHR (WHM, MM), and an Achievers in Medical Sciences and T. Chen Fong award (DA). RWT is an AHFMR Scientist.

Open Access This article is distributed under the terms of the Creative Commons Attribution Noncommercial License which permits any noncommercial use, distribution, and reproduction in any medium, provided the original author(s) and source are credited.

\section{References}

1. Czubayko U, Sultan F, Thier P, Schwarz C (2001) Two types of neurons in the rat cerebellar nuclei as distinguished by membrane potentials and intracellular fillings. J Neurophysiol 85(5):2017-2029

2. Aizenman CD, Linden DJ (1999) Regulation of the rebound depolarization and spontaneous firing patterns of deep nuclear neurons in slices of rat cerebellum. J Neurophysiol 82(4):1697-1709

3. Uusisaari M, Obata K, Knopfel T (2007) Morphological and electrophysiological properties of GABAergic and nonGABAergic cells in the deep cerebellar nuclei. J Neurophysiol 97(1):901-911

4. Jahnsen H (1986) Extracellular activation and membrane conductances of neurones in the guinea-pig deep cerebellar nuclei in vitro. J Physiol 372:149-168

5. Raman IM, Gustafson AE, Padgett D (2000) Ionic currents and spontaneous firing in neurons isolated from the cerebellar nuclei. J Neurosci 20(24):9004-9016
6. Gardette R, Debono M, Dupont JL, Crepel F (1985) Electrophysiological studies on the postnatal development of intracerebellar nuclei neurons in rat cerebellar slices maintained in vitro. II. Membrane conductances. Brain Res 352(1):97-106

7. Molineux ML, McRory JE, McKay BE, Hamid J, Mehaffey WH, Rehak R et al (2006) Specific T-type calcium channel isoforms are associated with distinct burst phenotypes in deep cerebellar nuclear neurons. Proc Natl Acad Sci USA 103 (14):5555-5560

8. Molineux ML, Mehaffey WH, Tadayonnejad R, Anderson D, Tennent AF, Turner RW (2008) Ionic factors governing rebound burst phenotype in rat deep cerebellar neurons. J Neurophysiol 100(5):2684-2701

9. Llinas R, Muhlethaler M (1988) Electrophysiology of guinea-pig cerebellar nuclear cells in the in vitro brain stem-cerebellar preparation. J Physiol 404:241-258

10. Zheng N, Raman IM (2009) Ca currents activated by spontaneous firing and synaptic disinhibition in neurons of the cerebellar nuclei. J Neurosci 29(31):9826-9838

11. Molineux ML, Fernandez FR, Mehaffey WH, Turner RW (2005) A-type and T-type currents interact to produce a novel spike latency-voltage relationship in cerebellar stellate cells. J Neurosci 25(47):10863-10873

12. Aizenman CD, Huang EJ, Linden DJ (2003) Morphological correlates of intrinsic electrical excitability in neurons of the deep cerebellar nuclei. J Neurophysiol 89:1738-1747

13. Aizenman CD, Manis PB, Linden DJ (1998) Polarity of longterm synaptic gain change is related to postsynaptic spike firing at a cerebellar inhibitory synapse. Neuron 21(4):827835

14. Gardette R, Debono M, Dupont JL, Crepel F (1985) Electrophysiological studies on the postnatal development of intracerebellar nuclei neurons in rat cerebellar slices maintained in vitro. I. Postsynaptic potentials. Brain Res 351(1):47-55

15. Zhang W, Shin JH, Linden DJ (2004) Persistent changes in the intrinsic excitability of rat deep cerebellar nuclear neurons induced by EPSPs or IPSP bursts. J Physiol (Lond) 561.3:703-19

16. Tadayonnejad R, Mehaffey WH, Anderson D, Turner RW (2009) Reliability of triggering postinhibitory rebound bursts in deep cerebellar neurons. Channels 3(3):1-7

17. Alvina K, Walter JT, Kohn A, Ellis-Davies G, Khodakhah K (2008) Questioning the role of rebound firing in the cerebellum. Nat Neurosci 11(11):1256-1258

18. Armstrong DM, Cogdell B, Harvey RJ (1973) Response of interpositus neurones to nerve stimulation in chloralose anesthetized cats. Brain Res 55(2):461-466

19. McCrea RA, Bishop GA, Kitai ST (1977) Electrophysiological and horseradish peroxidase studies of precerebellar afferents to the nucleus interpositus anterior. II. Mossy fiber system. Brain Res 122(2):215-228

20. Kitai ST, McCrea RA, Preston RJ, Bishop GA (1977) Electrophysiological and horseradish peroxidase studies of precerebellar afferents to the nucleus interpositus anterior. I. Climbing fiber system. Brain Res 122(2):197-214

21. Ito M, Yoshida M, Obata K, Kawai N, Udo M (1970) Inhibitory control of intracerebellar nuclei by the purkinje cell axons. Exp Brain Res 10(1):64-80

22. Rowland NC, Jaeger D (2008) Responses to tactile stimulation in deep cerebellar nucleus neurons result from recurrent activation in multiple pathways. J Neurophysiol 99(2):704-717

23. Ruigrok TJ (1997) Cerebellar nuclei: the olivary connection. Prog Brain Res 114:167-192

24. Gruart A, Pastor AM, Armengol JA, Delgado-Garcia JM (1997) Involvement of cerebellar cortex and nuclei in the genesis and control of unconditioned and conditioned eyelid motor responses. Prog Brain Res 114:511-528 
25. Chen FP, Evinger C (2006) Cerebellar modulation of trigeminal reflex blinks: interpositus neurons. J Neurosci 26(41):1056910576

26. Rowland NC, Jaeger D (2005) Coding of tactile response properties in the rat deep cerebellar nuclei. J Neurophysiol 94 (2):1236-1251

27. Ohtsuka K, Noda H (1991) Saccadic burst neurons in the oculomotor region of the fastigial nucleus of macaque monkeys. J Neurophysiol 65(6):1422-1434

28. Armstrong DM, Cogdell B, Harvey R (1975) Effects of afferent volleys from the limbs on the discharge patterns of interpositus neurones in cats anaesthetized with alpha-chloralose. J Physiol 248(2):489-517

29. MacKay WA (1988) Unit activity in the cerebellar nuclei related to arm reaching movements. Brain Res 442(2):240-254

30. Schwartz AB, Ebner TJ, Bloedel JR (1987) Responses of interposed and dentate neurons to perturbations of the locomotor cycle. Exp Brain Res 67(2):323-338

31. Delgado-Garcia JM, Gruart A (2005) Firing activities of identified posterior interpositus nucleus neurons during associative learning in behaving cats. Brain Res Brain Res Rev 49 (2):367-376

32. Pugh JR, Raman IM (2006) Potentiation of mossy fiber EPSCs in the cerebellar nuclei by NMDA receptor activation followed by postinhibitory rebound current. Neuron 51(1):113-123

33. Hamid J, Peloquin JB, Monteil A, Zamponi GW (2006) Determinants of the differential gating properties of Cav3.1 and Cav3.3 T-type channels: a role of domain IV? Neuroscience 143 (3):717-728

34. Chan-Palay V (1977) Cerebellar dentate nucleus: organization, cytology and transmitters. Springer, Berlin

35. Sultan F, Czubayko U, Thier P (2003) Morphological classification of the rat lateral cerebellar nuclear neurons by principal component analysis. J Comp Neurol 455(2):139-155

36. Armstrong DM, Rawson JA (1979) Activity patterns of cerebellar cortical neurones and climbing fibre afferents in the awake cat. J Physiol 289:425-448

37. Cody FW, Moore RB, Richardson HC (1981) Patterns of activity evoked in cerebellar interpositus nuclear neurones by natural somatosensory stimuli in awake cats. J Physiol 317:1-20

38. LeDoux MS, Hurst DC, Lorden JF (1998) Single-unit activity of cerebellar nuclear cells in the awake genetically dystonic rat. Neuroscience 86(2):533-545

39. Gauck V, Jaeger D (2000) The control of rate and timing of spikes in the deep cerebellar nuclei by inhibition. J Neurosci 20 (8):3006-3016

40. Mouginot D, Gahwiler BH (1995) Characterization of synaptic connections between cortex and deep nuclei of the rat cerebellum in vitro. Neuroscience 64(3):699-712

41. Alvina K, Khodakhah K (2008) Selective regulation of spontaneous activity of neurons of the deep cerebellar nuclei by N-type calcium channels in juvenile rats. J Physiol 586(10):2523-2538

42. Feng SS, Jaeger D (2008) The role of SK calcium-dependent potassium currents in regulating the activity of deep cerebellar nucleus neurons: a dynamic clamp study. Cerebellum 7(4):542-546

43. Shakkottai VG, Chou CH, Oddo S, Sailer CA, Knaus HG, Gutman GA et al (2004) Enhanced neuronal excitability in the absence of neurodegeneration induces cerebellar ataxia. J Clin Invest 113(4):582-590

44. Muri R, Knopfel T (1994) Activity induced elevations of intracellular calcium concentration in neurons of the deep cerebellar nuclei. J Neurophysiol 71(1):420-428

45. Hurlock EC, Bose M, Pierce G, Joho RH (2009) Rescue of motor coordination by Purkinje cell-targeted restoration of Kv3.3 channels in Kcnc3-null mice requires Kcnc1. J Neurosci 29 (50):15735-15744
46. Jahnsen H (1986) Electrophysiological characteristics of neurones in the guinea-pig deep cerebellar nuclei in vitro. J Physiol 372:129-147

47. Chen S, Hillman DE (1993) Colocalization of neurotransmitters in the deep cerebellar nuclei. J Neurocytol 22(2):81-91

48. Bagnall MW, Zingg B, Sakatos A, Moghadam SH, Zeilhofer HU, Lac S (2009) Glycinergic projection neurons of the cerebellum. J Neurosci 29(32):10104-10110

49. Uusisaari M, Knopfel T (2010) GlyT2+ neurons in the lateral cerebellar nucleus. Cerebellum 9:42-55

50. Mainen ZF, Sejnowski TJ (1996) Influence of dendritic structure on firing pattern in model neocortical neurons. Nature 382 (6589):363-366

51. Quadroni R, Knopfel T (1994) Compartmental models of type A and type B guinea pig medial vestibular neurons. J Neurophysiol 72(4):1911-1924

52. Alvina K, Ellis-Davies G, Khodakhah K (2009) T-type calcium channels mediate rebound firing in intact deep cerebellar neurons. Neuroscience 158(2):635-641

53. Perez-Reyes E, Cribbs LL, Daud A, Lacerda AE, Barclay J, Williamson MP et al (1998) Molecular characterization of a neuronal low-voltage-activated T-type calcium channel. Nature 391(6670):896-900

54. Lee JH, Daud AN, Cribbs LL, Lacerda AE, Pereverzev A, Klockner U et al (1999) Cloning and expression of a novel member of the low voltage-activated T-type calcium channel family. J Neurosci 19(6):1912-1921

55. McRory JE, Santi CM, Hamming KS, Mezeyova J, Sutton KG, Baillie DL et al (2001) Molecular and functional characterization of a family of rat brain T-type calcium channels. J Biol Chem 276(6):3999-4011

56. McKay BE, McRory JE, Molineux ML, Hamid J, Snutch TP, Zamponi GW et al (2006) $\mathrm{Ca}(\mathrm{V}) 3$ T-type calcium channel isoforms differentially distribute to somatic and dendritic compartments in rat central neurons. Eur J NeuroSci 24 (9):2581-2594

57. Kim D, Song I, Keum S, Lee T, Jeong MJ, Kim SS et al (2001) Lack of the burst firing of thalamocortical relay neurons and resistance to absence seizures in mice lacking alpha(1G) T-type $\mathrm{Ca}(2+)$ channels. Neuron 31(1):35-45

58. Lee S, Han TH, Sonner PM, Stern JE, Ryu PD, Lee SY (2008) Molecular characterization of T-type $\mathrm{Ca}(2+)$ channels responsible for low threshold spikes in hypothalamic paraventricular nucleus neurons. Neuroscience 155(4):1195-1203

59. Iftinca M, Hamid J, Chen L, Varela D, Tadayonnejad R, Altier C et al (2007) Regulation of T-type calcium channels by Rhoassociated kinase. Nat Neurosci 10(7):854-860

60. Wilcox KS, Gutnick MJ, Christoph GR (1988) Electrophysiological properties of neurons in the lateral habenula nucleus: an in vitro study. J Neurophysiol 59(1):212-225

61. Pugh JR, Raman IM (2008) Mechanisms of potentiation of mossy fiber EPSCs in the cerebellar nuclei by coincident synaptic excitation and inhibition. J Neurosci 28(42):10549-10560

62. Gauck V, Thomann M, Jaeger D, Borst A (2001) Spatial distribution of low- and high-voltage-activated calcium currents in neurons of the deep cerebellar nuclei. J Neurosci 21 (15): RC158

63. Lee JH, Gomora JC, Cribbs LL, Perez-Reyes E (1999) Nickel block of three cloned T-type calcium channels: low concentrations selectively block alpha1H. Biophys J 77(6):3034-3042

64. Iftinca M, McKay BE, Snutch TP, McRory JE, Turner RW, Zamponi GW (2006) Temperature dependence of T-type calcium channel gating. Neuroscience 142(4):1031-1042

65. Randall AD, Tsien RW (1997) Contrasting biophysical and pharmacological properties of T-type and R-type calcium channels. Neuropharmacology 36(7):879-893 
66. Raman IM, Bean BP (1999) Ionic currents underlying spontaneous action potentials in isolated cerebellar Purkinje neurons. $\mathrm{J}$ Neurosci 19(5):1663-1674

67. Joho RH, Hurlock EC (2009) The role of Kv3-type potassium channels in cerebellar physiology and behavior. Cerebellum 8:323-333

68. Alonso-Espinaco V, Elezgarai I, Diez-Garcia J, Puente N, Knopfel T, Grandes P (2008) Subcellular localization of the voltage-gated potassium channels $\mathrm{Kv} 3.1 \mathrm{~b}$ and $\mathrm{Kv} 3.3$ in the cerebellar dentate nucleus of glutamic acid decarboxylase 67green fluorescent protein transgenic mice. Neuroscience 155 (4):1059-1069

69. Smith MR, Nelson AB, Du Lac S (2002) Regulation of firing response gain by calcium-dependent mechanisms in vestibular nucleus neurons. J Neurophysiol 87(4):2031-2042

70. Berkefeld H, Sailer CA, Bildl W, Rohde V, Thumfart JO, Eble S et al (2006) BKCa-Cav channel complexes mediate rapid and localized $\mathrm{Ca}^{2+}$-activated $\mathrm{K}^{+}$signaling. Science 314(5799):615-620

71. Marrion NV, Tavalin SJ (1998) Selective activation of $\mathrm{Ca}^{2+}$ activated $\mathrm{K}^{+}$channels by co-localized $\mathrm{Ca}^{2+}$ channels in hippocampal neurons. Nature 395(6705):900-905

72. Cueni L, Canepari M, Lujan R, Emmenegger Y, Watanabe M, Bond CT et al (2008) T-type $\mathrm{Ca}^{2+}$ channels, SK2 channels and SERCAs gate sleep-related oscillations in thalamic dendrites. Nat Neurosci 11(6):683-692

73. Jimenez C, Bourinet E, Leuranguer V, Richard S, Snutch TP, Nargeot J (2000) Determinants of voltage-dependent inactivation affect Mibefradil block of calcium channels. Neuropharmacology 39(1):1-10

74. Afshari FS, Ptak K, Khaliq ZM, Grieco TM, Slater NT, McCrimmon DR et al (2004) Resurgent Na currents in four classes of neurons of the cerebellum. J Neurophysiol 92(5):2831-2843

75. Ghamari-Langroudi M, Bourque CW (2002) Flufenamic acid blocks depolarizing afterpotentials and phasic firing in rat supraoptic neurones. J Physiol 545(Pt 2):537-542

76. Li Z, Hatton GI (1997) $\mathrm{Ca}^{2+}$ release from internal stores: role in generating depolarizing after-potentials in rat supraoptic neurones. J Physiol 498(Pt 2):339-350

77. Telgkamp P, Raman IM (2002) Depression of inhibitory synaptic transmission between Purkinje cells and neurons of the cerebellar nuclei. J Neurosci 22(19):8447-8457

78. Palkovits M, Mezey E, Hamori J, Szentagothai J (1977) Quantitative histological analysis of the cerebellar nuclei in the cat. I. Numerical data on cells and on synapses. Exp Brain Res 28(1-2):189-209

79. Garwicz M, Ekerot CF, Jorntell H (1998) Organizational principles of cerebellar neuronal circuitry. News Physiol Sci 13:26-32

80. Telgkamp P, Padgett DE, Ledoux VA, Woolley CS, Raman IM (2004) Maintenance of high-frequency transmission at Purkinje to cerebellar nuclear synapses by spillover from boutons with multiple release sites. Neuron 41(1):113-126

81. Pugh JR, Raman IM (2005) GABAA receptor kinetics in the cerebellar nuclei: evidence for detection of transmitter from distant release sites. Biophys J 88(3):1740-1754

82. Sastry BR, Morishita W, Yip S, Shew T (1997) GABA-ergic transmission in deep cerebellar nuclei. Prog Neurobiol 53 (2):259-271

83. Shin SL, De Schutter E (2006) Dynamic synchronization of Purkinje cell simple spikes. J Neurophysiol 96(6):3485-3491

84. De Schutter E, Steuber V (2009) Patterns and pauses in Purkinje cell simple spike trains: experiments, modeling and theory. Neuroscience 162(3):816-826

85. Pedroarena CM, Schwarz C (2003) Efficacy and short-term plasticity at GABAergic synapses between Purkinje and cerebellar nuclei neurons. J Neurophysiol 89(2):704-715
86. De Zeeuw CI, Berrebi AS (1995) Postsynaptic targets of Purkinje cell terminals in the cerebellar and vestibular nuclei of the rat. Eur J NeuroSci 7(11):2322-2333

87. de Zeeuw CI, Berrebi AS (1996) Individual Purkinje cell axons terminate on both inhibitory and excitatory neurons in the cerebellar and vestibular nuclei. Ann N Y Acad Sci 781:607610

88. Staley KJ, Soldo BL, Proctor WR (1995) Ionic mechanisms of neuronal excitation by inhibitory GABAA receptors. Science 269(5226):977-981

89. Billups D, Attwell D (2002) Control of intracellular chloride concentration and GABA response polarity in rat retinal $\mathrm{ON}$ bipolar cells. J Physiol 545(Pt 1):183-198

90. Gavrikov KE, Nilson JE, Dmitriev AV, Zucker CL, Mangel SC (2006) Dendritic compartmentalization of chloride cotransporters underlies directional responses of starburst amacrine cells in retina. Proc Natl Acad Sci USA 103(49):18793-18798

91. Staley KJ, Proctor WR (1999) Modulation of mammalian dendritic $\mathrm{GABA}(\mathrm{A})$ receptor function by the kinetics of $\mathrm{Cl}^{-}$ and $\mathrm{HCO}_{3}{ }^{-}$transport. J Physiol 519(Pt 3):693-712

92. Saitow F, Murano M, Suzuki H (2009) Modulatory effects of serotonin on GABAergic synaptic transmission and membrane properties in the deep cerebellar nuclei. J Neurophysiol 101 (3): 1361-1374

93. Woolf NJ, Butcher LL (1989) Cholinergic systems in the rat brain: IV. Descending projections of the pontomesencephalic tegmentum. Brain Res Bull 23(6):519-540

94. Takeuchi Y, Kimura H, Sano Y (1982) Immunohistochemical demonstration of serotonin-containing nerve fibers in the cerebellum. Cell Tissue Res 226(1):1-12

95. Olson L, Fuxe K (1971) On the projections from the locus coeruleus noradrealine neurons: the cerebellar innervation. Brain Res 28(1):165-171

96. Schwartz JC, Arrang JM, Garbarg M, Pollard H, Ruat M (1991) Histaminergic transmission in the mammalian brain. Physiol Rev 71(1):1-51

97. Mouginot D, Gahwiler BH (1996) Presynaptic GABAB receptors modulate IPSPs evoked in neurons of deep cerebellar nuclei in vitro. J Neurophysiol 75(2):894-901

98. Morishita W, Sastry BR (1995) Pharmacological characterization of pre- and postsynaptic GABAB receptors in the deep nuclei of rat cerebellar slices. Neuroscience 68(4):1127-1137

99. Pedroarena CM, Kamphausen S (2008) Glycinergic synaptic currents in the deep cerebellar nuclei. Neuropharmacology 54 (5):784-795

100. Zhang W, Linden DJ (2006) Long-term depression at the mossy fiber-deep cerebellar nuclear synapse. J Neuroscience 26:69356944

101. Gauck V, Jaeger D (2003) The contribution of NMDA and AMPA conductances to the control of spiking in neurons of the deep cerebellar nuclei. J Neurosci 23(22):8109-8118

102. Knopfel T (2007) Two new non-competitive mGlu1 receptor antagonists are potent tools to unravel functions of this mGlu receptor subtype. Br J Pharmacol 151(6):723-724

103. Zheng N, Raman IM (2010) Synaptic inhibition, excitation, and plasticity in neurons of the cerebellar nuclei. Cerebellum 9:56 66

104. Dreyfus FM, Tscherter A, Errington AC, Renger JJ, Shin HS, Uebele VN et al (2010) Selective T-type calcium channel block in thalamic neurons reveals channel redundancy and physiological impact of I(T)window. J Neurosci 30(1):99-109

105. Straka H, Vibert N, Vidal PP, Moore LE, Dutia MB (2005) Intrinsic membrane properties of vertebrate vestibular neurons: function, development and plasticity. Prog Neurobiol 76(6):349392 
106. Lambert RC, Bessaih T, Leresche N (2006) Modulation of neuronal T-type calcium channels. CNS Neurol Disord Drug Targets 5(6):611-627

107. Becker AJ, Pitsch J, Sochivko D, Opitz T, Staniek M, Chen CC et al (2008) Transcriptional upregulation of Cav3.2 mediates epileptogenesis in the pilocarpine model of epilepsy. J Neurosci 28(49):13341-13353

108. Uusisaari M, Knopfel T (2008) GABAergic synaptic communication in the GABAergic and non-GABAergic cells in the deep cerebellar nuclei. Neuroscience 156(3):537-549

109. Hansen AJ (1985) Effect of anoxia on ion distribution in the brain. Physiol Rev 65(1):101-148

110. Lisman JE (1997) Bursts as a unit of neural information: making unreliable synapses reliable. Trends Neurosci 20(1):38-43

111. Chacron MJ, Longtin A, Maler L (2004) To burst or not to burst? J Comput Neurosci 17(2):127-36

112. Sherman SM (2001) Tonic and burst firing: dual modes of thalamocortical relay. Trends Neurosci 24(2):122-126

113. Alitto HJ, Weyand TG, Usrey WM (2005) Distinct properties of stimulus-evoked bursts in the lateral geniculate nucleus. J Neurosci 25(2):514-523

114. Lesica NA, Stanley GB (2004) Encoding of natural scene movies by tonic and burst spikes in the lateral geniculate nucleus. J Neurosci 24(47):10731-10740

115. Oswald AM, Chacron MJ, Doiron B, Bastian J, Maler L (2004) Parallel processing of sensory input by bursts and isolated spikes. J Neurosci 24(18):4351-4362
116. Fanselow EE, Sameshima K, Baccala LA, Nicolelis MA (2001) Thalamic bursting in rats during different awake behavioral states. Proc Natl Acad Sci USA 98(26):15330-15335

117. Lesica NA, Weng C, Jin J, Yeh CI, Alonso JM, Stanley GB (2006) Dynamic encoding of natural luminance sequences by LGN bursts. PLoS Biol 4(7):e209

118. Metzner W, Koch C, Wessel R, Gabbiani F (1998) Feature extraction by burst-like spike patterns in multiple sensory maps. J Neurosci 18(6):2283-2300

119. Oswald AM, Doiron B, Maler L (2007) Interval coding. I. Burst interspike intervals as indicators of stimulus intensity. J Neurophysiol 97(4):2731-2743

120. Bengtsson FL, Carl-Fredrik E, Jorntell H (2008) Convergence of Purkinje cell synaptic input to deep cerebellar nuclear neurons in vivo. Proc Soc Neurosci, Washington

121. Delgado-Garcia JM, Gruart A (2006) Building new motor responses: eyelid conditioning revisited. Trends Neurosci 29 (6):330-338

122. Ohtsuka K, Noda H (1995) Discharge properties of Purkinje cells in the oculomotor vermis during visually guided saccades in the macaque monkey. J Neurophysiol 74(5):1828-1840

123. Ohtsuka K, Noda H (1992) Burst discharges of mossy fibers in the oculomotor vermis of macaque monkeys during saccadic eye movements. Neurosci Res 15(1-2):102-114

124. Ouardouz M, Sastry BR (2000) Mechanisms underlying LTP of inhibitory synaptic transmission in the deep cerebellar nuclei. J Neurophysiol 84(3):1414-1421 